Article

\title{
Bio-Optical Characterization and Ocean Colour Inversion in the Eastern Lagoon of New Caledonia, South Tropical Pacific
}

\author{
Luciane Rafaele Favareto ${ }^{1, *(1)}$, Natália Rudorff ${ }^{1, *(1)}$, Milton Kampel ${ }^{1}$ (D), Robert Frouin ${ }^{2}$ (1), \\ Rüdiger Röttgers ${ }^{3}$, David Doxaran ${ }^{4}$, Hiroshi Murakami ${ }^{5}$ and Cécile Dupouy ${ }^{6}$ (D) \\ 1 National Institute for Space Research, Remote Sensing Division, Av. dos Astronautas 1758, São Jose dos \\ Campos 12227-010, Brazil; milton.kampel@inpe.br \\ 2 Scripps Institution of Oceanography, University of California San Diego, 8810 Shellback Way, La Jolla, CA \\ 92093, USA; rfrouin@ucsd.edu \\ 3 Institute of Coastal Research Helmholtz-Zentrum Geesthacht, Max-Planck-Str. 1, D-21502 Geesthacht, \\ Germany; rroettgers@hzg.de \\ 4 University of Sorbonne, CNRS, Villefranche Oceanographic Laboratory, LOV, 181 Chemin du Lazaret, \\ 06230 Villefranche-sur-Mer, France; doxaran@obs-vlfr.fr \\ 5 Japan Aerospace Exploration Agency, Tsukuba, Ibaragi 305-8505, Japan; murakami.hiroshi.eo@jaxa.jp \\ 6 Aix-Marseille University, Univ. Toulon, IRD, CNRS, Mediterranean Institute of Oceanography, UM110, \\ MIO, at Centre IRD de Nouméa, BP A5, 98848 Nouméa, New Caledonia, France; cecile.dupouy@ird.fr \\ * Correspondence: lu.rafaele@gmail.com (L.R.F.); natalia.rudorff@inpe.br (N.R.); \\ Tel.: +55-012-3208-7687 (N.R.)
}

Received: 29 May 2018; Accepted: 29 June 2018; Published: 2 July 2018

\begin{abstract}
The Eastern Lagoon of New Caledonia (ELNC) is a semi-enclosed system surrounded by an extensive coral reef barrier. The system has been suffering impacts from climate variability and anthropogenic activities, including mining exploitation. Satellite monitoring is thus an essential tool to detect such changes. The present study aimed to assess the bio-optical variability of the ELNC and examine the applicability of ocean colour algorithms, using in situ bio-optical and radiometric data, collected during the March 2014 CALIOPE 2 cruise. The chlorophyll $a$ concentration (Chla) varied from $0.13-0.72 \mathrm{mg} \cdot \mathrm{m}^{-3}$, and the coastal stations were spectrally dominated by non-algal particles (NAP) and coloured dissolved organic matter $(\mathrm{CDOM})(>80 \%$ of the total non-water absorption at $443 \mathrm{~nm}$ ), due to the contribution of allochthonous sources. The phytoplankton specific absorption was generally lower (mean, $0.049 \mathrm{~m}^{2} \cdot \mathrm{mg} \mathrm{Chl} a^{-1}$ ) than typical values observed for the corresponding Chla range, as well as the spectral slopes of the absorption of CDOM plus NAP $\left(a_{\mathrm{dg}}\right)\left(\right.$ mean, $\left.0.016 \mathrm{~nm}^{-1}\right)$ and of the particle backscattering coefficient $\left(b_{\mathrm{bp}}\right)$ (mean, $0.07 \mathrm{~nm}^{-1}$ ). The remote sensing reflectance obtained using two in-water approaches and modelled from Inherent Optical Properties (IOPs) showed less than $20 \%$ relative percent differences (RPD). Chla estimates were highly biased for the empirical (OC4 and OC3) and semi-analytical (GSM, QAA, GIOP, LMI) algorithms, especially at the coastal stations. Excluding these stations, the GSM01 yielded the best retrievals with 35-40\% RPD. $a_{\mathrm{dg}}(443)$ was well retrieved by all algorithms with $\sim 18 \% \mathrm{RPD}$, and $b_{\mathrm{bp}}(443)$ with $\sim 40 \%$ RPD. Turbidity algorithms also performed reasonably well (30\% RPD), showing the capacity and usefulness of the derived products to monitor the water quality of the ELNC, provided accurate atmospheric correction of the satellite data. Regionally tuned algorithms may potentially improve the Chl $a$ retrievals, but better parameterization schemes that consider the spatiotemporal variability of the specific IOPs are still needed.
\end{abstract}

Keywords: marine remote sensing reflectance; bio-optical properties; ocean colour algorithms; eastern lagoon of New Caledonia; Southwest Tropical Pacific Ocean 


\section{Introduction}

Tropical lagoons and coral reefs are among the marine ecosystems with highest biodiversity that provide to man various services such as tourism, fishery and coastal protection. These environments however, are highly vulnerable to natural and anthropogenic changes. Coral reefs are especially sensitive to changes in sedimentation rates, seawater acidification, as well as, the increase in incident ultraviolet (UV) radiation and sea surface temperature [1,2]. Several authors have shown and predicted even greater changes in the biological communities of these ecosystems with loss of biodiversity and an increased dominance of macroalgae, as consequence of these stressors [3-6].

The Eastern Lagoon of New Caledonia (ELNC) (Southwest Pacific Ocean) is a semi-enclosed tropical system, surrounded by an extensive coral reef barrier $(\sim 300 \mathrm{~km})$, with high biodiversity, and declared as part of the UNESCO World Heritage List since 2008 [7]. Despite of its importance, this ecosystem has been suffering from severe environmental and anthropogenic stressors [8]. In February 2016 it experienced massive coral bleaching [2] and is still under recovery. The east coast of New Caledonia is also rich in nickel and cobalt, and mining exploitation activities have accelerated soil erosion processes and impacted the water quality of the lagoon throughout the past years $[9,10]$. Hence, monitoring programs are essential to understand the processes affecting the water quality and coral reef ecosystem of the ELNC, to detect changes timelessly, and to improve protection programs.

Ocean colour remote sensing is a powerful tool to analyse the environmental variability at different spatial and temporal scales, providing synoptic information of the surface ocean. It is thus a valuable resource to monitor and detect changes in coastal areas with high vulnerability, such as lagoons and coral reefs [11]. The challenge however, is to obtain accurate estimation of the apparent (e.g., above-water remote sensing reflectance, $R_{\mathrm{rs}}(\lambda)$ ) and inherent (e.g., absorption and backscattering coefficients) optical properties in coastal environments with optically complex waters [12].

To validate and develop accurate satellite observations, one needs first to build a robust in situ database. Although in situ measurements are made carefully, minimizing uncertainties is a great challenge and could propagate adversely to even be amplified in the final products [13]. The $R_{\mathrm{rs}}$ measurements can have high uncertainties $(>30 \%)$ depending on the environmental conditions and the acquisition and processing methods $[14,15]$. Determination of Inherent Optical Properties (IOPs) can also be a challenge depending on the water type (concentration of each constituent) and instrument [16-18]. Once the optical properties are accurately obtained, the next challenge is to apply an inversion algorithm to estimate through the $R_{\mathrm{rs}}$, the IOPs, i.e., phytoplankton $\left(a_{\text {phy }}\right)$, Coloured Dissolved Organic Matter (CDOM) $\left(a_{\text {cdom }}\right)$, and non-algal particles (NAP) $\left(a_{\text {nap }}\right)$ light absorption coefficients, and the backscattering coefficient of suspended particles $\left(b_{\mathrm{bp}}\right)$, or related biogeochemical properties, e.g., chlorophyll $a$ concentration (Chla) [19].

Empirical algorithms that directly relate $R_{\mathrm{rs}}$ to the IOPs, or biogeochemical properties, through statistical approaches, are usually more accurate for water types where one optical constituent dominates, i.e., phytoplankton, CDOM, or non-algal particles, while the others co-vary. The applicability of these algorithms is, however, highly restricted to the data set from which it was built (spatially and temporally) $[20,21]$. The SeaWiFS OC4 and Moderate Resolution Imaging Spectroradiometer (MODIS) OC3M [22] algorithms were developed using an in situ global data base [13] covering different oceanic and coastal regions, apart from areas with direct influence of continental sources. They exploit the sensitivity of the blue:green $R_{\mathrm{rs}}$ band ratio (at the $\sim$ maximum (blue) and minimum (green) phytoplankton absorption peaks) to Chla in a fourth order polynomial function. To optimize the applicability of the algorithm over a wide range of Chla $\left(0.1-75 \mathrm{mg} \cdot \mathrm{m}^{-3}\right)$ a maximum band ratio selection scheme $(443,490,510: 555)$ is applied to enhance the signal to noise relation. Despite of the simplicity of the empirical algorithms, they have been widely used to obtain surface Chla maps from satellites, being in many cases more accurate than other approaches.

Semi-analytical inversion algorithms estimate the optical properties of each constituent separately, i.e., $a_{\mathrm{phy}}, a_{\mathrm{dg}}$ (absorption of CDOM plus NAP) and $b_{\mathrm{bp}}$, providing more versatile schemes. Such algorithms should be more suitable for optically complex waters, with independent variation of the 
in-water constituents. However, the inversion problem is not trivial, and can lead to multiple solutions, with different combinations of IOPs. Moreover, some spectral parameters need to be set as constants or empirically derived before the inversion. These parameters, however, are known to vary depending on the phytoplankton community structure and physiological state [23,24], particle assemblage (types and size distribution) [25], and CDOM sources and photo-degradation state [26]. For global ocean applications average values and relations used for these specific optical properties can be suitable [19]. But for complex coastal waters one needs to seek the optimal approach and parameterization scheme [12].

The Garver-Siegel-Maritorena-GSM01 [27,28] uses the quadratic function of Gordon et al. [29] to invert all the IOPs simultaneously from spectral $R_{\mathrm{rs}}(412,443,490,510,555$ and $670 \mathrm{~nm})$, using a non-linear minimum square regression fit. The spectral shape parameters of $a_{\text {phy }}\left(a_{\text {phy }}{ }^{*}\right)$, $b_{\mathrm{bp}}\left(S_{\mathrm{bbp}}\right)$ and $a_{\mathrm{dg}}\left(S_{\mathrm{dg}}\right)$ are fixed and obtained by an optimal global fit using a large in situ and synthetic data set for Case 1 waters [28]. This scheme is referred as a bottom-up strategy (BUS) [12].

The Quasi-Analytical Algorithm-QAA [30,31] uses a different approach denoted as a top-down strategy (TDS) [12]. It is implemented in different steps to retrieve each of the IOPs separately. First the total absorption and backscattering coefficients are obtained using an adapted version of the Gordon et al. [29] quadratic function [30] (and some empirical relations), then the total absorption is partitioned into the CDM (CDOM plus NAP) and phytoplankton contributions, analytically. In this case the spectral parameters are not fixed, but they are empirically derived using $R_{\mathrm{rs}}$ band ratios and relations obtained with global in situ data bases [13], to encompass at least some of the variability of the specific IOPs.

The Generalized IOP_GIOP [32] follows the same rationale of the GSM01 to determine the IOPs, but it allows the inclusion of steps where the user can choose different settings for the determination of the spectral parameters. The standard setup uses the geometric parameters obtained from Gordon et al. [29]; the $S_{\mathrm{bbp}}$ and $S_{\mathrm{dg}}$ derived from empirical relations with the $R_{\mathrm{rs}}$ blue:green ratio [30] (same for the QAA), and the $a_{\text {phy }}{ }^{*}$ obtained from Bricaud et al. [23], using the Chla determined by OC4 [22]. This algorithm was developed as a joint effort to combine different approaches taking advantage of the most suitable algorithms and data sets available for the users to set in their own applications, being the most versatile scheme.

The Linear Matrix Inversion (LMI) [33-35] uses spectral $R_{\mathrm{rs}}$ (at 443, 490 and $555 \mathrm{~nm}$ ), to algebraically derive $a_{\text {phy }}(443), a_{\mathrm{cdm}}(443)$ and $b_{\mathrm{bp}}(443)$, using a linear matrix scheme, with fixed spectral parameters. Murakami et al. [36] and Murakami and Dupouy [37] developed a regional version of the LMI algorithm using data collected from various campaigns since 2006, mostly at the Southwest lagoon of New Caledonia, to parameterize the specific IOPs. They obtained better results than using the globally tuned LMI, suggesting that site-specific variability of the specific IOPs have significant impacts on ocean colour retrievals in New Caledonia coastal lagoons and regionally tuned approaches could potentially improve the retrievals.

Surface water turbidity algorithms have also been used to monitor the water quality of coastal environments using ocean colour satellites. Ouillon et al. [38] developed a regional empirical algorithm for New Caledonia coastal lagoons (with $R_{\mathrm{rs}}(565)$ for $<1$ Nephelometric Turbidity Units - NTU), and a global algorithm for tropical coastal waters (with $R_{\mathrm{rs}}$ at 412, 620 and $681 \mathrm{~nm}$ for $<25$ NTU). Dogliotti et al. [39] recently proposed a single global semi-analytical algorithm for all water types based on marine surface reflectance $(\rho)$ at $645 \mathrm{~nm}$ for clear-moderately turbid waters $(<15$ Formazine Nephelometric Unit - FNU), and $\rho$ (859) for turbidity above 15 and up to 1000 FNU. This approach has shown applicability over various coastal regions, contrasting with other approaches that are dedicated solely to specific regions [39]. In situ campaigns for the collection of optical properties in New Caledonia coastal waters have been conducted since 2001 [40-42]. In the South Western Tropical lagoon, a series of bio-optical measurements and pigment data were collected in the frame of the VALHYBIO project [43-49]. These data sets were used for studies regarding the validation and development of empirical [46] and semi-analytical bio-optical algorithms [36,37], the application of a biogeochemical model [47] and the determination of bathymetry by satellite imagery [48,49]. The ELNC (on the other side of the island), has been sampled only more recently 
in the context of the TREMOLO project [9], with three in situ campaigns up to date: the CALIOPE 1 (October 2011), CALIOPE 2 (March 2014), and CALIOPE 3 (March 2016, [10]).

In the present study, the results of the CALIOPE 2 cruise for the distribution of the bio-optical properties are described, and the applicability of common ocean colour algorithms to retrieve IOPs and biogeochemical properties in the ELNC waters are evaluated. The work was divided in the following topics: (i) analysis of the distribution of the bio-optical and biogeochemical properties; (ii) comparison of in situ radiometric measurements, with different in-water approaches and a closure experiment; and (iii) comparison of ocean colour algorithms for optical and biogeochemical properties applied to in situ $R_{\text {rs }}$. Our goal was to characterize the optical variability of the ELNC waters during the CALIOPE 2 campaign and identify the most suitable ocean colour algorithms and products that may be applied to future satellite monitoring programs.

\section{Materials and Methods}

\subsection{Study Area}

Located in the western South Pacific Ocean, the reef structures and ecosystems of New Caledonia extend between the latitudes of $18^{\circ} \mathrm{S}$ and $23^{\circ} \mathrm{S}$ and longitudes of $162^{\circ} \mathrm{E}$ and $168^{\circ} \mathrm{E}$. The reefs permeate the entire island forming lagoons surrounded by a continental shelf with a steep slope. The ELNC has approximately $300 \mathrm{~km}$ of extension, located between the villages of Yaté and Hienghène (Figure 1). It is the deepest lagoon in New Caledonia with maximum depths of $\sim 80 \mathrm{~m}$, and is semi-enclosed by a coral reef barrier located between 5 to $25 \mathrm{~km}$ from the coastline. The lagoon is connected to the adjacent Pacific Ocean, through strait passages that allow the intrusion of oligotrophic oceanic waters forced by tides, trade winds, and circulation of the external Vauban Current [50]. On the continental side, there are many small and medium size rivers that contribute to the system, as well as several mining sites [10,51]. Compared to the western lagoons, the ELNC is deeper and has more restricted connections to the open ocean, through strait passages $[9,10,47]$. The austral spring-summer is generally hot and rainy, with more intensive showers extending through January to March, whereas the austral autumn-winter (March to September) is generally dryer and marked by more intensive southeast trade winds [52,53]. The coastal lagoons of New Caledonia are typically dominated by oligo-mesotrophic waters throughout the year $\left(\sim 0.3 \mathrm{mg} \cdot \mathrm{m}^{-3}\right.$ of $\mathrm{Chl} a$ ), with strong influence of the adjacent ocean. However, during the rainy season, and especially after intensive rainfall events, that wash out the eroded soil, organic and inorganic sediments, as well as nutrients that enhance phytoplankton growth, are carried into the lagoon increasing the water turbidity and altering the trophic state $[9,10,42]$.

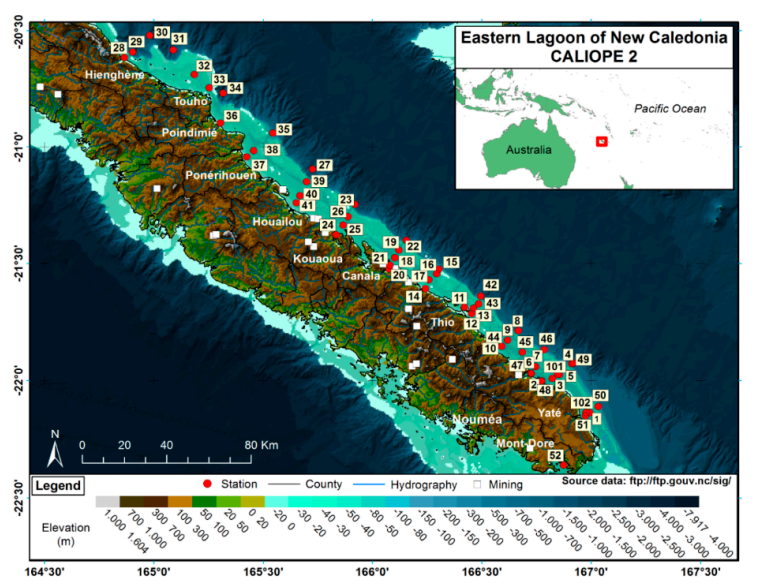

Figure 1. Map of the study area indicating the location of the sampling stations from the CALIOPE 2 conducted from 8 to 21 of March 2014 in the Eastern Lagoon of New Caledonia (ELNC). Data from bathymetry, hydrography, villages, and mining sites were downloaded from ftp:/ ftp.gouv.nc/sig/ accessed on 5 February 2014. 


\subsection{Oceanographic Campaign}

The oceanographic cruise CALIOPE 2, was conducted from 8 to 21 of March 2014. A total of 55 stations were sampled from the south (Yaté) to the north of the lagoon (Hienghène), distributed within 12 transects perpendicular to the coastline, up to the open ocean, across the coral reef barrier (Figure 1). At each station collections were made to determine: (i) meteo-oceanographic conditions, including: wind speed, sea surface temperature, and salinity (with a CTD probe SBE19); (ii) biogeochemical properties, i.e., turbidity and Chla; (iii) bio-optical properties, i.e., phytoplankton, CDOM and NAP light absorption coefficients, and marine $b_{\mathrm{bp}}$, and (iv) radiometric properties, i.e., downwelling solar irradiance and upwelling radiance.

\subsection{Biogeochemical and Bio-Optical Properties}

In situ water turbidity was obtained by a ECO FLNTU (Wetlabs Inc., New Caledonia, France) turbidimeter profiler that measures the light scattered at 140 degrees from a $700 \mathrm{~nm}$ LED light source, and converts the signal into NTU using calibration coefficients and the Formazin Standard provided by the manufacturer. Surface water turbidity was obtained by averaging the profile measurements within the first $3 \mathrm{~m}$.

The collection and processing of the bio-optical data are the same as described in Dupouy et al., [9,40-42]. Vertical profiles of the backscattering coefficient $\left(b_{\mathrm{b}}, \mathrm{m}^{-1}\right)$ were measured using a Hydroscat- 6 (HobiLabs) scatterometer calibrated 1 month before the cruise, with $10 \mathrm{~nm}$ bands centred at 442, 488,510, $550 \mathrm{~nm}$, and $20 \mathrm{~nm}$ bands at 620 and $670 \mathrm{~nm}$. Data was processed using the manufacturer calibration files and volume scattering function $(\beta)$, and corrected for the path length signal loss due to absorption (sigma correction) [54]. The seawater $b_{\mathrm{b}}$ used to obtain the $b_{\mathrm{bp}}$ was determined following Twardowski et al. [17] adjusted for the mean salinity of the lagoon. The surface water $b_{\mathrm{bp}}$ value was determined by averaging the first depths $(1-5 \mathrm{~m})$, to avoid noise caused by bubble clouds and in-water perturbations.

For analysis of the light absorption coefficients and Chla, water samples were collected at a sub-surface depth of $\sim 2 \mathrm{~m}$ with a rosette Niskin bottle system. Samples for determination of phytoplankton pigments and the particulate absorption coefficient were immediately filtered on board (1-2 L), using $25 \mathrm{~mm}$ GFF $(0.7 \mu \mathrm{m}$ nominal pore size). The filters were stored in liquid nitrogen for laboratory analysis. The Chla was determined by two methods: (i) using an adapted fluorometric method after $90 \%$ methanol extraction, and subtracting for pheopigments after acidification [9,40-42], and (ii) by High Performance Liquid Chromatography (HPLC) [55] (analysed by Crystal Thomas, NASA laboratory). The mean percent difference between the two measurements was lower than $10 \%$ indicating good accuracy. We used the HPLC total Chla (TChla) as the reference value and the fluorimetric Chla to determine the standard deviation as an uncertainty metric.

The CDOMl light absorption $\left(a_{\text {cdom }}\right)$ from $250-750 \mathrm{~nm}$ was measured on board using the UltraPath method (World Precision Instruments Inc.), after filtration of the sample through a $0.2 \mu \mathrm{m}$ pore sized membrane filter, pre-washed in a $10 \% \mathrm{HCl}$ solution and rinsed with MilliQ water. The blank reference was prepared to have similar salinity with addition of pre-combusted $\mathrm{NaCl}$. The path length was adjusted from 2 to $0.1 \mathrm{~m}$ according to each sample. Salinity and temperature corrections were performed following Röttgers et al. [56].

The particulate absorption coefficient $\left(a_{\mathrm{p}}\right)$ was determined using the Quantitative Filter Technique (QFT) adapted from Mitchell [57], following Röttgers et al. [18], with a portable Integrating Cavity Absorption Meter setup (QFT-ICAM). First the total light absorption of the particulate material is measured on the filter sample using the ICAM spectrophotometer to determine $a_{\mathrm{p}}$. Then the filter is exposed to a solution of $10 \% \mathrm{NaOCl}$ for $\sim 5 \mathrm{~min}$, to bleach the phytoplankton pigments, and is measured again in the spectrophotometer to determine the light absorption of the non-algal particles $\left(a_{\text {nap }}\right)[58,59]$. The path length amplification factor $(\beta)$ due to filter multiple scattering was determined for each sample by comparing the particulate absorption measured on the filter with the spectrophotometer, and $a_{\mathrm{p}}$ measured with the Point Source Integrating Cavity Absorption 
Meter (PSICAM), following Röttgers \& Doerffer [59], Röttgers et al. [56] and Röttgers et al. [18]. At last, the phytoplankton absorption coefficient $\left(a_{\text {phy }}\right)$ was determined by subtracting $a_{\text {nap }}$ from $a_{\mathrm{p}}$. Total absorption (a) was obtained by summing $a_{\mathrm{p}}+a_{\text {cdom }}$ with the pure water absorption coefficient $\left(a_{\mathrm{w}}\right)$ [60]. The mean percent difference between $a_{\mathrm{p}}$ pseudo triplicates (water filtered from the same cast) were less than $10 \%$ within the visible spectrum $(400-700 \mathrm{~nm})$.

For the $a_{\mathrm{p}}$ PSICAM measurements, first the cavity is filled with purified water and absorption measurements are taken to obtain a mean reference spectrum between 350 and $720 \mathrm{~nm}$. In the following, the water sample is poured into the cavity and the total absorption is measured. The cavity is washed and filled again with purified water and then filled with filtered water samples $(0.2 \mu \mathrm{m})$ to determine $a_{\mathrm{cdom}}$. The particulate absorption is then determined by subtracting $a_{\text {cdom }}$ and the pure water reference absorptions from the total absorption.

Since standard ocean colour algorithms do not differentiate CDOM absorption from $a_{\text {nap }}$, as they have a similar spectral dependency, for the purpose to evaluate the ocean colour algorithms, we summed these terms, referring to them as $a_{\mathrm{dg}}$. The spectral slopes $(S)$ of $a_{\text {cdom }}\left(S_{\text {cdom }}\right), a_{\text {nap }}\left(S_{\text {nap }}\right)$ and $a_{\mathrm{dg}}\left(S_{\mathrm{dg}}\right)$ were determined by applying an exponential fit to each spectrum between 350 and $500 \mathrm{~nm}$. For $b_{\mathrm{bp}}$ the spectral slope $\left(S_{\mathrm{bbp}}\right)$ was determined using a power law fit for each station within 443-555 nm. The specific phytoplankton absorption coefficient $\left(a_{\text {phy }}{ }^{*}\right)$ was determined by normalizing $a_{\text {phy }}$ with Chla.

\subsection{Radiometric Measurements}

Radiometric data was collected using two types of in-water radiometers: (i) the free-falling Satlantic profiler and (ii) TriOS sensors, attached to a floating structure (Figure 2C,D), for comparison and uncertainty determination. The Satlantic free-falling profiler radiometer (Hyperpro-II) (Figure 2A,B) measures radiance between 350 and $800 \mathrm{~nm}$ (3.3 nm bandwidth). With this instrument radiometric data was obtained at 40 stations with in-water profiles of downwelling irradiance $\left(E_{\mathrm{d}}(\lambda, \mathrm{z})\right)$ and upwelling radiance $\left(L_{\mathrm{u}}(\lambda, \mathrm{z})\right)$. Data was pre-processed using the Prosoft software with the instrument calibration files, and some profile editions to eliminate noise (using tilt and velocity thresholds). To make the profiles even smoother, filtering out noise caused by wavy facets and bubble clouds, a second order polynomial fit was also applied to each profile. To extrapolate $E_{\mathrm{d}}(\lambda, z)$ and $L_{\mathrm{u}}(\lambda, \mathrm{z})$ to just below surface values $\left(0^{-}\right)$, the diffuse light attenuation coefficients $\left(K_{\mathrm{d}}(\lambda)\right.$ and $K_{\mathrm{u}}(\lambda)$, respectively) were determined using the intercept of the linear regression fit of the log transformed data (assuming an homogeneous profile). The depth interval used to determine $K_{\mathrm{d}}$ and $K_{\mathrm{u}}$ varied at each station from 5-15 m, depending on the size of the profile and avoiding noisy intervals. After the extrapolation of $L_{\mathrm{u}}(\lambda)$ and $E_{\mathrm{d}}(\lambda)$ to $0^{-}$, they were extrapolated to just above surface $\left(0^{+}\right)$, i.e., $L_{\mathrm{w}}$ and $E_{\mathrm{d}}\left(0^{+}\right)$, using air-water transmittance factors [61]. The $R_{\mathrm{rs}}$ determined with the Satlantic free-falling profiler $\left(R_{\mathrm{rS}} \mathrm{S}\right)$ was finally obtained by the ratio of $L_{\mathrm{w}} / E_{\mathrm{d}}\left(0^{+}\right)$.

The light penetration depth $\left(Z_{90}\right)$, above which approximately $90 \%$ of the $R_{\mathrm{rs}}$ signal is originated, can be approximated by $1 / K_{\mathrm{d}}(\lambda)$ [62]. Hence, $\mathrm{Z}_{90}$ was also determined for each station, within the visible spectral range $(400-700 \mathrm{~nm})$, to verify possible influences of bottom reflectance on the above-water $R_{\mathrm{rs}}$ within the stations sampled at the ELNC.

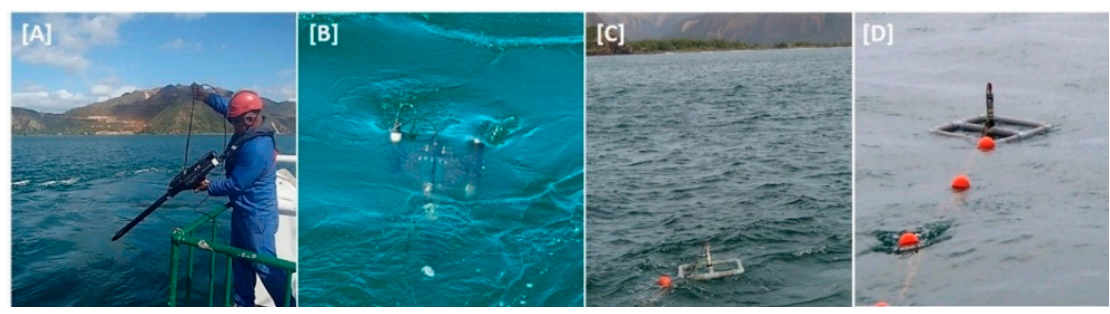

Figure 2. Photographs of the Satlantic Hyperpro-II free-falling radiometer (A,B) and the TriOS-RAMSES in-water radiometer attached to a floating polyvinyl chloride (PVC) frame (C,D). 
Radiometric data obtained with the TriOS-RAMSES sensors was measured using two hyperspectral radiometers SAM-ARC-Vis: one for the sub-surface $(\sim 2 \mathrm{~cm}) L_{\mathrm{u}}(\lambda)$ deployed with an adapted floating system (Figure 2C,D), and another for the above-water downwelling irradiance $\left(E_{\mathrm{s}}(\lambda)\right.$ ) installed at upper most level of the vessel (deck sensor). These measurements were made at 49 stations (9 more than with the Satlantic profiler). The TriOS instruments measure radiance and irradiance from 320 to $950 \mathrm{~nm}$, with $3.3 \mathrm{~nm}$ bandwidth resolution ( $7 \mathrm{~nm}$ bandwidth). To minimize platform shading effects and in-water perturbations which may bias in-water profiling systems winched beside the vessel $[15,63]$, the in-water TriOS sensor was attached to a PVC floating structure connected to a cable with buoys, and deployed to drift away and collect sub-surface $L_{\mathrm{u}}$ data at least $15 \mathrm{~m}$ distant from the platform [64]. The sub-surface $L_{\mathrm{u}}$ was extrapolated to surface water leaving radiance $\left(L_{\mathrm{w}}\right)$ using air-water transmittance factors [61], and the above-water TriOS $R_{\mathrm{rs}}\left(R_{\mathrm{rs}} \mathrm{T}\right)$ was obtained with the ratio of $L_{\mathrm{w}} / E_{\mathrm{s}}$.

For the comparisons between the two approaches, and to further apply the radiometric data to the ocean colour algorithms, the hyperspectral $R_{\mathrm{rs}}$ measurements were used to simulate correspondent bands of the MODIS-Aqua sensor centred at 412, 443, 490, 510 and $555 \mathrm{~nm}$ with $10 \mathrm{~nm}$ bandwidth. Both the Satlantic and TriOS $R_{\mathrm{rs}}$ data were corrected for variations in solar zenith angle (SZA) to obtain equivalent values for the Sun at zenith, using $f / Q$ factors provided by Morel et al. [65].

A closure experiment was also performed to evaluate the consistency between the radiometric measurements and bio-optical data. The experiment was approached by comparing the measured $R_{\mathrm{rs}}$ with forward modelled $R_{\mathrm{rs}}$, using the measured absorption $(a)$ and backscattering $\left(b_{\mathrm{b}}\right)$ coefficients. The measured $R_{\mathrm{rs}}$ used for these comparisons (as well as for the application of the bio-optical algorithms), were the ones obtained from the TriOS instruments, since there was a higher number of sampled stations $(\mathrm{N}=49)$. The standard deviation of the $R_{\mathrm{rs}}$ obtained by the two in-water approaches, was used as an uncertainty estimate for the in situ radiometry. The modelled $R_{\mathrm{rs}}$ was obtained using approximations of the radiative-transfer equation (RTE), with environmental and bidirectional factors following Morel et al. [65], Gordon et al. [29], and Park and Ruddick [66]. The Gordon et al. [29] approximation uses a quadratic function with two factors i.e., $l_{1}=0.0949$ and $l_{2}=0.0794$, that relate the sub-surface remote sensing reflectance $\left(r_{\mathrm{rs}}\right)$ to the IOPs i.e., $r_{\mathrm{rs}}=l_{1}\left(b_{\mathrm{b}} /\left(a+b_{\mathrm{b}}\right)\right)+l_{1}\left(b_{\mathrm{b}} /\left(a+b_{\mathrm{b}}\right)\right)^{2}$. This approximation is simple and very practical for ocean colour applications, being used in common inversion algorithms e.g., GSM, QAA, GIOP. The Morel et al. [65] approximation uses a ratio of two factors $(f / Q)$, that are spectrally dependent, and vary with the $\mathrm{Chl} a$, to account for variations in the scattering phase function, when relating $R_{\mathrm{rs}}$ to the IOPs i.e., $R_{r s}=\Re f / Q\left(b_{\mathrm{b}} / a\right)(\Re$ is the air-water transmittance factor). This approximation is more elaborated, but appropriate solely for open ocean or coastal waters where phytoplankton and covarying detritus dominates the light absorption and scattering, as the scattering phase function is dependent solely on Chla, and $b_{\mathrm{b}}$ should be much smaller than $a$. Since the ELNC is, however, also subjected to river outflows that may potentially carry in suspended sediments, we also tested the Park and Ruddick [66] approach. The approximation in this case, uses a fourth order polynomial function that relates $R_{\mathrm{rs}}$ to the IOPs, with four environmental and bidirectional factors $\left(g_{i(\lambda)}, i=1-4\right)$ that vary with the ratio of $b_{\mathrm{bp}}: b_{\mathrm{b}}$ (as well as wind speed-considering nadir viewing geometry and Sun at Zenith) to account for variations in the volume scattering phase function with the bulk particle assemblage. The standard deviation between the modelled $R_{\mathrm{rs}}\left(R_{\mathrm{rs}} \mathrm{RTE}\right.$ ) obtained by the 3 approximations was used as an uncertainty measure. Other sources due to propagation of IOP uncertainties and inelastic scattering (i.e., Raman scattering) were not quantified, but only discussed for simplicity.

The comparisons between the $R_{\mathrm{rs}}$ measurements, as well as with the forward model retrievals, were made using standard metrics of radiometry inter-comparisons, i.e., the coefficient of determination $\left(R^{2}\right)$, the root mean square error (RMSE), the relative mean percent difference (RPD) (in absolute values) (RPD $\left.=\Sigma\left[\left|x_{1}-x_{2}\right| / x_{2}\right] / N\right) \times 100$ ), where $x_{2}$ is the reference), and the unbiased percentage difference (UPD) $\left.\left.\left(\mathrm{UPD}=\Sigma\left[\left(x_{1}-x_{2}\right) /\left(\left(x_{1}+x_{2}\right) / 2\right)\right] / N\right) \times 100\right)\right)[14,15]$. The UPD presupposes that all methods are somewhat biased and indicates there is an over (positive) or under 
(negative) estimation of a method in respect to the other. The RPD was used to quantify the total error relative to a least biased "reference".

\subsection{Bio-Optical Algorithms}

Ocean colour bio-optical algorithms were tested using the in situ measured $R_{\mathrm{rs}}$ (from the TriOS instrument). For Chla determinations the algorithms that were tested for the ELNC were: the empirical OC3M and OC4 [22], and the semi-analytical GSM01 [27,28] and the GIOP [32]. To estimate the absorption and backscattering coefficients we applied the GSM01, GIOP, QAA [30] and the LMI, in this case regionally tuned for New Caledonia coastal lagoons [36,37].

Surface water turbidity algorithms were also applied to the ELNC with in situ data obtained during the CALIOPE 2 campaign, testing 3 approaches: (i) the regional algorithm proposed by Ouillon et al. [38]; (ii) the global algorithm for tropical coastal waters also proposed by Ouillon et al. [38] and (iii) the single global algorithm for all water types proposed by Dogliotti et al. [39]. Although turbidity measurements use the same chemical standard i.e., Formazin, they are specified in different units according to methods and instruments. As this may be a source of discrepancy in the application of the algorithms, we specify the corresponding units used in each approach. Turbidity measured by Ouillon et al. [38] was obtained using a SeaPoint optical turbidimeter that measures the scattered light at $880 \mathrm{~nm}$, in a broad viewing angle of 15-150 degrees, and the units are given in Formazin Turbidity Units (FTU). Turbidity measured by Dogliotti et al. [39] were obtained using portable HACH 2100P and 2100QIS turbidimeters, which measure the side-scattered light at $860 \mathrm{~nm}$, at 90 degrees, and the units are given in Formazin Nephelometric Units (FNU). As previously described, we used a ECO FLNTU (Wetlabs Inc., New Caledonia, France) turbidimeter that measures the scattered light at $700 \mathrm{~nm}$ at 140 degrees, and the units are specified in Nephelometric Turbidity Units (NTU).

All the retrievals were compared to the in situ measurements using statistical metrics of linear regression: the slope, $R^{2}$ and RMSE, and the relative mean percent difference (RPD).

\section{Results and Discussion}

\subsection{Environmental and Bio-Optical Characterization}

During the CALIOPE 2 campaign, in late summer 2014, although cloud coverage was high, the rainy season was late, and contribution of river runoff was lower than during CALIOPE 3, but still somewhat higher than during CALIOPE 1 in the dry winter season $[9,10]$. The wind intensity during CALIOPE 2 was also much higher (up to $16 \mathrm{~m} \cdot \mathrm{s}^{-1}$ ) than CALIOPE 1 [9], contributing to the higher water turbidity with a well-mixed water column and bottom re-suspension in shallow areas near the coast (as noticed in the vertical turbidity profiles-not shown). The biophysical parameters of the surface waters had a relatively small range of variability, with water temperature varying from $26.2-28.1^{\circ} \mathrm{C}$, salinity between 35.2-34.7 and turbidity between 0.12-1.09 NTU. The southern tip of the lagoon was characterized by colder, more saline and less turbid waters (Figure 3), suggesting a greater influence of oceanic oligotrophic waters due to local circulation $[9,10]$. Coastal upwelling, which occurs especially during spring and summer, in southwest New Caledonia [44,67], can also contribute to bring colder and more saline waters into the southern lagoons [44,47]. The inner coastal stations, especially in the central lagoon, between the villages of Houailou and Thio, were the ones with lowest salinity and highest turbidity (Figure 3). Besides of river runoff, this region has 11 mining sites that contribute to increasing surface water turbidity and accumulating sediments within the lagoon, especially after intensive rainy events that wash out the eroded soil $[9,42]$.

The surface Chla varied from $0.136 \pm 0.001$ to $0.725 \pm 0.112 \mathrm{mg} \cdot \mathrm{m}^{-3}$, with an average of $0.370 \pm 0.163 \mathrm{mg} \cdot \mathrm{m}^{-3}$, presenting characteristics of oligo-mesotrophic waters. Higher Chla values were obtained at the coastal stations between the villages of Canala and Thio, which had lower salinity $(\sim 34.8)$ and higher turbidity ( 1 NTU), indicating that a greater influence of river runoff enhances phytoplankton growth in this central sector of the lagoon. Bottom resuspension forced by strong and persistent winds $\left(>7 \mathrm{~m} \cdot \mathrm{s}^{-1}\right)$ also favours the phytoplankton growth at these shallower stations 
(11-17 m) [9]. Hence, during CALIOPE 2, the surface Chla was higher than the observed during CALIOPE 1 in the dry and calm winter season (October 2011) (mean $\sim 0.21 \mathrm{mg} \cdot \mathrm{m}^{-3}$ and maximum $0.60 \mathrm{mg} \cdot \mathrm{m}^{-3}$ ) [9], suggesting a higher contribution of river runoff and resuspension processes, even though the rainy season was late. In the following summer campaign, CALIOPE 3 (March 2016), which captured a greater influence of continental drainage and river runoff, the surface Chl $a$ had a close average $\left(0.37 \pm 0.7 \mathrm{mg} \cdot \mathrm{m}^{-3}\right)$, but a higher range of variability, i.e., $0.02-3.51 \mathrm{mg} \cdot \mathrm{m}^{-3}$, compared to CALIOPE 2 [10].
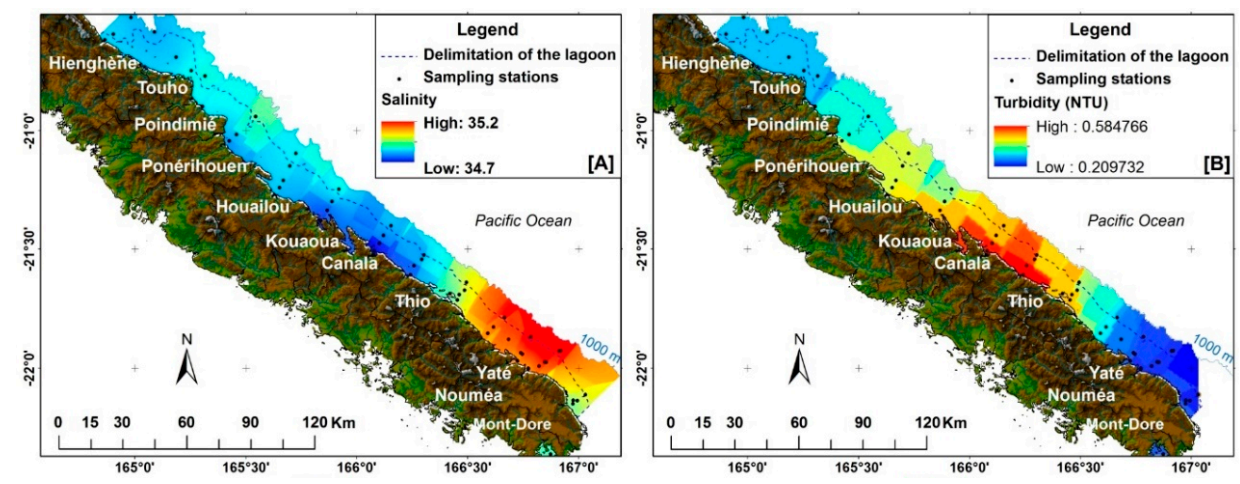

Figure 3. Surface distribution maps of the surface water salinity (A) and turbidity (B) in the ELNC, during CALIOPE 2 (March 2014) cruises.

The $a_{\text {phy }}(443)$ varied from $0.007 \pm 0.0003$ to $0.037 \pm 0.002 \mathrm{~m}^{-1}$, with an average of $0.018 \pm 0.007 \mathrm{~m}^{-1}$ (Figure $4 \mathrm{~A})$, and a positive co-variation with Chla $\left(\mathrm{R}^{2}=0.86\right)$. Variability in the relation between $a_{\text {phy }}(443)$ and Chla can be due to non-linear packaging effects associated to the phytoplankton community structure and photo-adaptation processes $[27,28,31]$. The specific absorption coefficient $a_{\text {phy }}{ }^{*}(443)$ (normalized by Chla) varied from 0.032 to $0.067 \mathrm{~m}^{2} \cdot \mathrm{mgChl} a^{-1}$, with an average of $0.049 \pm 0.008 \mathrm{~m}^{2} \cdot \mathrm{mgChl} a^{-1}$ (Figure 4A), typical of populations mostly dominated by nanoplankton cells [28], as found in New Caledonia coastal lagoons $[10,43,44]$. The lowest $a_{\text {phy }}{ }^{*}(443)$ values $\left(\sim 0.032 \mathrm{~m}^{2} \cdot \mathrm{mgChl} a^{-1}\right)$ were obtained at the coastal stations (e.g., stations 14, 16, 20 and 24), which had higher TChla $\left(>0.6 \mathrm{mg} \cdot \mathrm{m}^{3}\right)$ and higher proportions of Fucoxanthin, suggesting the dominance of diatoms $(>40 \%)$ (following the relation proposed by Uitz et al. [68] and updated by Hirata et al. [69] with the diagnostic pigments determined by HPLC). The highest $a_{\text {phy }}{ }^{*}(443)$ values $\left(\sim 0.067 \mathrm{~m}^{2} \cdot \mathrm{mgChl} a^{-1}\right)$ were obtained at the stations across the coral reef barrier, at the shelf slope (>300 m deep) (e.g., stations 22 and 23), with lower TChl $a\left(<0.2 \mathrm{mg} \cdot \mathrm{m}^{3}\right)$ and higher proportions of diagnostic pigments of picoplankton groups (Zeaxanthin, Chl $b$ and DVChla), suggesting the dominance of these groups $(>60 \%)[68,69]$. The negative relation between $a_{\text {phy }}{ }^{*}(443)$ and Chla associated to the dominance of different phytoplankton groups (and size classes) has been well reported in other works $[23,34,70]$.
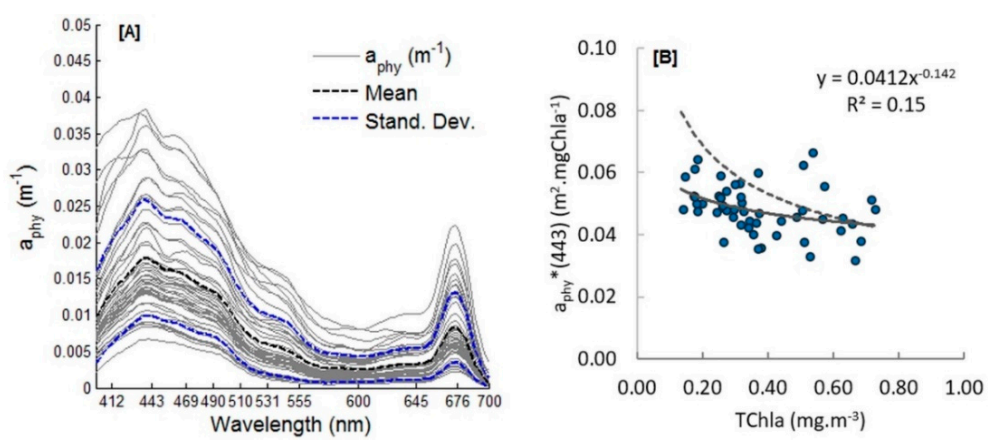

Figure 4. Phytoplankton absorption ( $\left.a_{\mathrm{phy}}\right)$ spectra (A) and specific phytoplankton absorption coefficient $\left(a_{\text {phy }}{ }^{*}\right)$ at $443 \mathrm{~nm}$ versus the TChla, with the power law regression fit (solid line) and the Bricaud et al. [23] fit for reference (dashed line) $(\mathbf{B})$ (Number of samples $=52$ ). 
There was however a highly dispersive relation between $a_{\text {phy }}{ }^{*}(443)$ and Chla $\left(R^{2}=0.15\right)$, and with $a_{\text {phy }}{ }^{*}(443)$ values mostly below those expected for the correspondent $\mathrm{Chl} a$, according to the global relation obtained by Bricaud et al. [23] (Figure 4B). This denotes the high complexity of the ELNC waters with "local" variations of the specific optical properties ("local" meaning both in respect to the geographic region and season). A source of variability in the $a_{\text {phy }}{ }^{*}(443)$ could be also due to photo-acclimation processes [24,70]. Even with relatively low phytoplankton biomass (mean, $0.37 \mathrm{mg} \cdot \mathrm{m}^{-3}$ of $\mathrm{Chl} a$ ), these cells need to compete with NAP and CDOM (which have extra sources in the ELNC result of mining activities), to absorb the underwater light. This competition for light, at overlapping absorbing peaks, poses an additional condition for photo-acclimation processes, in which the phytoplankton cells need to increase its bulk absorbing capacity, increasing the intracellular $\mathrm{Chl} a$, and consequently increasing pigment shading effects, which diminishes $a_{\text {phy }}{ }^{*}$. Hence the phytoplankton cells of the ELNC may have lower $a_{\text {phy }}{ }^{*}$ values due to the "extra" light competition with CDOM and NAP absorption.

Part of the deviation from the "global" relation of $a_{\mathrm{phy}}{ }^{*}(443)$ and Chl $a$ could however, also be due to methodological issues. Stramski et al. [71] shows how using different methods and path length amplification factors (beta correction) can cause over than $30 \%$ differences for the $a_{\mathrm{p}}$ measurements. Particularly, they showed how the transmittance QFT method (as used to determine the $a_{\mathrm{phy}}(443)$ and Chla relation by Bricaud et al. [24]) tends to overestimate $a_{\text {phy }}(443)$ in respect to measurements obtained inside an integrating sphere (as used herein following Röttgers et al. [18]). This a problem to be considered when integrating data sets obtained from different cruises and analysed by different methods [71].

The $a_{\text {cdom }}(443)$ had a mean value of $0.014 \pm 0.005 \mathrm{~m}^{-1}$ (Figure 5A), and was more correlated to turbidity $\left(R^{2}=0.60\right)$ than $C h l a\left(R^{2}=0.31\right)$, indicating the influence of allochthonous sources in the lagoon. Martias et al. [10] made a thorough description of the different sources of CDOM in the ELNC, citing river runoff, coastal erosion (linked to mining activity), bottom re-suspension, as well as releases from the coral reef benthic community, besides of the autochthonous sources linked to the phytoplankton. The highest $a_{\text {cdom }}(443)$ values were observed at the coastal stations of the central sector (maximum $0.037 \mathrm{~m}^{-1}$ ) near the main rivers, and the lowest at the southern tip (minimum $0.004 \mathrm{~m}^{-1}$ ), with greater influence of oceanic waters [9]. Regarding the $a_{\text {cdom }}(\lambda)$ spectral slope $\left(S_{\text {cdom }}\right)$, the observed values were also similar to those reported at the other CALIOPE campaigns in the ELNC (mean, $0.017 \pm 0.002 \mathrm{~nm}^{-1}$ ), with the lowest values near the main rivers (minimum $0.014 \mathrm{~nm}^{-1}$ ) and highest (maximum $0.023 \mathrm{~nm}^{-1}$ ) at the southern sector and outside the reef barrier, where water transparency favours photo-oxidation processes $[10,26]$.
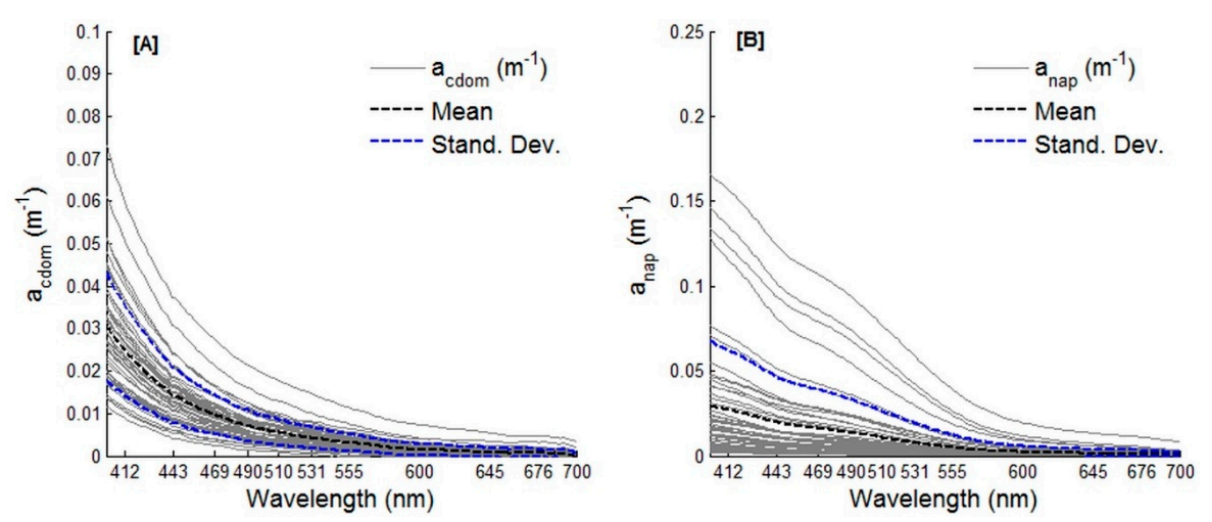

Figure 5. Coloured dissolved organic matter (CDOM) absorption $\left(a_{\mathrm{cdom}}\right)$ spectra $(\mathbf{A})$ and non-algal particles (NAP) absorption $\left(a_{\text {nap }}\right)$ spectra for each station, mean and standard deviation for all stations (B) (Number of samples $=52$ ). 
The $a_{\text {nap }}(443)$ was on average higher than $a_{\text {cdom }}(443)$, with a mean of $0.02 \pm 0.018 \mathrm{~m}^{-1}$ (Figure 5B). The highest values $\left(\sim 0.10 \mathrm{~m}^{-1}\right)$ were observed at the coastal stations near Kouaoua and Houailou, and the lowest at the southern tip of the lagoon $\left(\sim 0.001 \mathrm{~m}^{-1}\right)$. The distribution of $a_{\text {nap }}$ was well explained by turbidity $\left(R^{2}=0.92\right)$ and only weakly explained by $C h l a\left(R^{2}=0.4\right)$, indicating the contribution of allochthonous particles in the system. A positive linear correlation $\left(R^{2}=0.79\right)$ was obtained between $a_{\text {nap }}(443)$ and $a_{\text {cdom }}(443)$, suggesting that both components have some similar sources in the ELNC, including river runoff, erosion from mining sites, the coral reef, which can also be a source of NAP [10,72], besides autochthonous sources. The mean $a_{\text {nap }}$ spectral slope $\left(S_{\text {nap }}\right)$ was $\sim 0.010 \pm 0.002 \mathrm{~nm}^{-1}$, which is close to the average reported by Bricaud et al. [73] for stations collected in the surface layer of the southeast Pacific Ocean $\left(0.009 \pm 0.018 \mathrm{~nm}^{-1}\right)$, and somewhat lower than values obtained by Babin et al. [74] in coastal waters around Europe (mean $0.0123 \mathrm{~nm}^{-1}$, varying from $0.0116-0.013 \mathrm{~nm}^{-1}$ ). The highest $S_{\text {nap }}$ values $\left(\sim 0.013 \mathrm{~nm}^{-1}\right)$ were associated with the clearest oceanic oligotrophic waters, with lower $a_{\text {nap }}(443)$ values. The lowest $S_{\text {nap }}$ values $\left(\sim 0.006 \mathrm{~nm}^{-1}\right)$ were obtained at the turbid coastal stations near the mining sites, with higher $a_{\text {nap }}(443)$. An inverse relation between $S_{\text {nap }}$ and $a_{\text {nap }}$ was also obtained by Bricaud et al. [73], although with a high dispersion indicating a complex relation between the bulk particle pool and the coloured fraction. Although within a low range of variability Babin et al. [74] discussed that lower $S_{\text {nap }}$ values in coastal waters could be associated to a greater contribution of mineral particles. Summing the CDOM and NAP absorption coefficients, the mean spectral slope was $0.014 \pm 0.002 \mathrm{~nm}^{-1}$, varying from 0.009 to $0.020 \mathrm{~nm}^{-1}$.

It should be noted that there were spectral features in $a_{\text {nap }}(\lambda)$ deviated from a typical exponential curve, with a "shoulder"-like feature between 460-580 nm (Figure 5B). This feature could be due to iron absorption, adsorbed to the suspended sediments [74,75], as New Caledonia has iron-rich laterite soil [51] that is eroded and lixiviated into the lagoon especially near the mining sites [42].

The total light absorption by constituents other than pure seawater (i.e., $a_{\text {phy }}+a_{\text {nap }}+a_{\text {cdom }}$ ) at $443 \mathrm{~nm}$ was mainly dominated by NAP at the shallowest stations $(11-22 \mathrm{~m}$ ) located near the coastline (maximum, $69 \%$ ). At the deeper stations towards the reef barrier (>40 $\mathrm{m}$ depth) and across to the open ocean $(>75 \mathrm{~m})$, however, the non-water absorption was dominated either by phytoplankton (maximum, 64\%) or CDOM (maximum, 48\%) (Figure 6). The variability in the proportions of the absorption by each constituent within the ELNC is rather high for an oligo-mesotrophic tropical lagoon, with relatively clear waters ( $<1.09$ NTU). Even with a strong influence of the oligotrophic waters of the adjacent ocean, and a minor influence of river runoff due to the late rainy season, the ELNC still had several different sources that affected the water quality and imprinted a complex mixture of optically active constituents, during CALIOPE 2. This mixture poses higher challenges for bio-optical and biogeochemical remote sensing retrievals, especially for the constituents with the least optical influence.
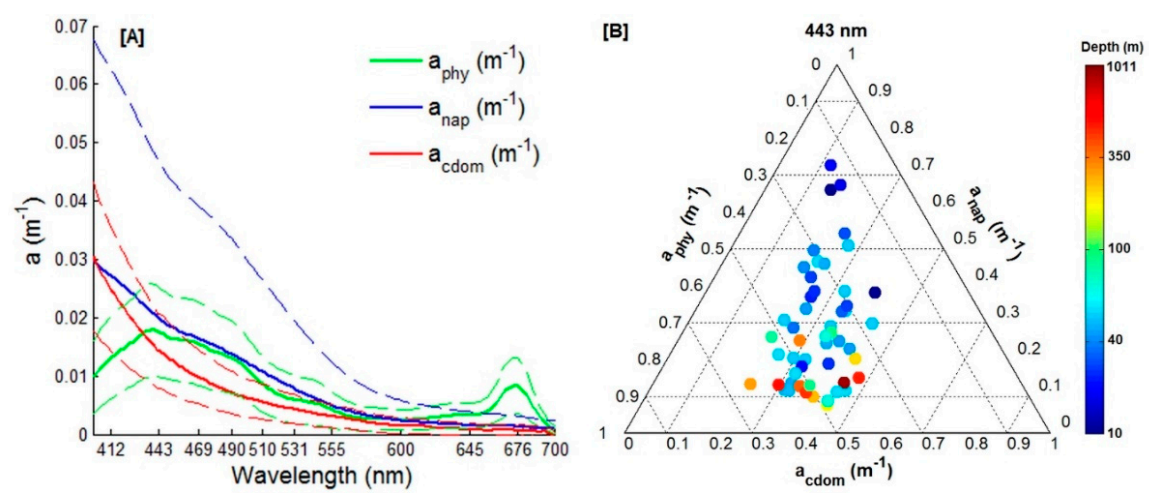

Figure 6. Mean (solid lines) and standard deviation (dashed lines) of phytoplankton absorption $\left(a_{\text {phy }}\right)$, Coloured dissolved organic matter (CDOM) absorption $\left(a_{\mathrm{cdom}}\right)$ and non-algal particles (NAP) absorption $\left(a_{\text {nap }}\right)$ (A). Ternary diagram with the proportions of $a_{\text {phy }}(443), a_{\text {cdom }}(443)$ and $a_{\text {nap }}(443)$ for each station (Number of samples $=51$ ) colour coded by the bottom depth $(\mathrm{m})(\mathbf{B})$. 
Regarding the marine $b_{\mathrm{bp}}$ at $443 \mathrm{~nm}$, the mean value obtained for the ELNC at CALIOPE 2 was $0.0036 \mathrm{~m}^{-1}$, with a high standard deviation of $\pm 0.004 \mathrm{~m}^{-1}$ (Figure 7A). The highest $b_{\mathrm{bp}}(443)$ values (maximum $0.018 \mathrm{~m}^{-1}$ ) were obtained at stations located near mining sites between Thio and Touho, in the central ELNC, as for the CALIOPE 1 campaign [9]. Higher $b_{\mathrm{bp}}(443)$ values $\left(\sim 0.0058 \mathrm{~m}^{-1}\right)$ were also observed at the northern sector of the lagoon at CALIOPE 2, probably favoured by re-suspension processes in the shallowest areas. For both campaigns, the southern sector had the clearest waters with the lowest $b_{\mathrm{bp}}(443)\left(\sim 0.004 \mathrm{~m}^{-1}\right)$, resembling clearer waters of the lagoons located in southwest New Caledonia [40-42], with greater influence of oceanic oligotrophic waters. The mean $b_{\mathrm{bp}}$ spectral slope $\left(S_{b \mathrm{bp}}\right)$ was $0.07 \pm 0.1 \mathrm{~nm}^{-1}$, which is small compared to the values typically obtained in open ocean waters (between 1 and $\sim 3$ ) [25] and likely associated with dominance of larger organic and inorganic particles.

The $b_{\mathrm{bp}}(555)$ had a weak positive relationship with Chla $\left(\mathrm{R}^{2}=0.34\right)$ and $a_{\mathrm{phy}}(443)\left(\mathrm{R}^{2}=0.42\right)$, but a strong relationship with $a_{\text {nap }}(443)\left(\mathrm{R}^{2}=0.84\right)$ (Figure $\left.7 \mathrm{~B}\right)$. This suggests that the non-algal particles present in relatively high proportions within the lagoon (especially at the central coastal stations) dominated the particulate light backscattering coefficient. The $a_{\text {cdom }}(443)$ also had an indirect but strong positive relation with $b_{\mathrm{bp}}(555)\left(\mathrm{R}^{2}=0.76\right)$, reinforcing that NAP and CDOM had some similar sources within the lagoon, which also influenced $b_{\mathrm{bp}}(555)$ e.g., river runoff, bottom re-suspension, mining activity, and the coral reef ecosystem, besides of the autochthonous sources.
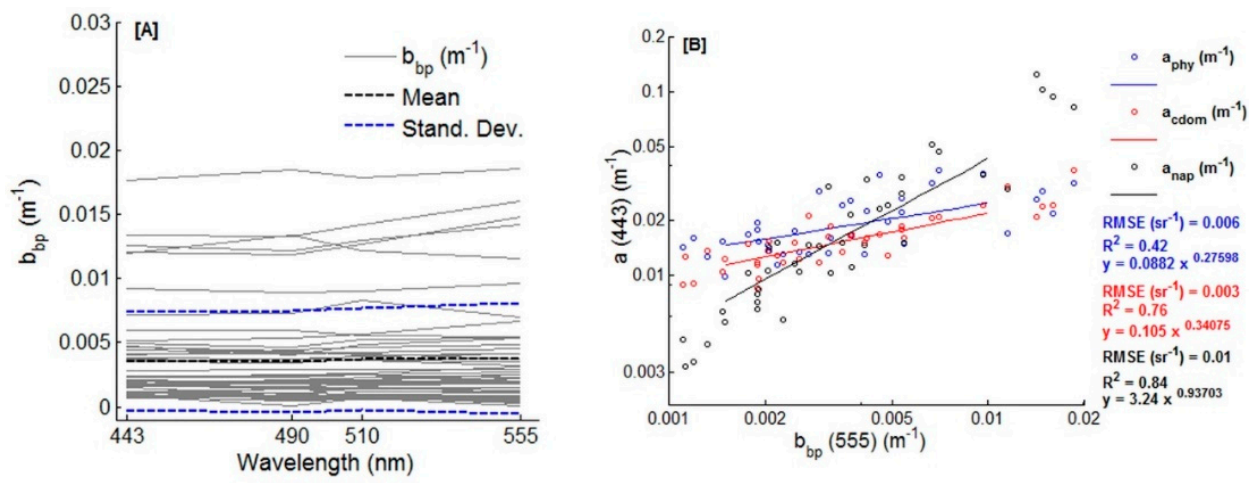

Figure 7. Particulate backscattering coefficient $\left(b_{\mathrm{bp}}\right)$ spectra for each station, mean and standard deviation (Number of samples $=52)(\mathbf{A})$. The $b_{\mathrm{bp}}$ at $555 \mathrm{~nm}$ versus phytoplankton absorption $\left(a_{\text {phy }}\right)$ at $443 \mathrm{~nm}$, Coloured dissolved organic matter (CDOM) absorption $\left(a_{\mathrm{cdom}}\right)$ at $443 \mathrm{~nm}$ and non-algal particles (NAP) absorption ( $\left.a_{\text {nap }}\right)$ at $443 \mathrm{~nm}$ with their mean square error, coefficient of determination $\left(\mathrm{R}^{2}\right)$ and the power law fit for the 51 stations sampled in ELNC (B) (axes in log10).

\subsection{In Situ Radiometry}

Of the 54 stations sampled during the CALIOPE 2 campaign, approximately $50 \%$ had cloud cover higher than $5 / 8$ and 14 stations were sampled with high SZA $\left(\geq 60^{\circ}\right)$ (early in the morning and late afternoon). Strong southwest winds were predominant during the data collection (average speed, $8.5 \mathrm{~m} \cdot \mathrm{s}^{-1}$ and maximum $\left.16 \mathrm{~m} \cdot \mathrm{s}^{-1}\right)$, indicating rough conditions for in situ radiometric measurements.

The $R_{\mathrm{rs}}$ spectra characteristic of clear waters with higher values at shorter wavelengths $(<490 \mathrm{~nm})$, were obtained at the deepest stations across the coral reef barrier, and at the southern and northern tips of the lagoon, where oceanic waters have greater intrusions. Near the main rivers, and especially close to the mining sites (between Thio and Ponérihouen), the $R_{\mathrm{rs}}$ spectra were characteristic of water types dominated by biogenic constituents, that absorb more light in the blue wavelengths, resulting in lower $R_{\mathrm{rs}}(<490 \mathrm{~nm})$, and mineral particles that are highly scattering and contribute to higher $R_{\mathrm{rs}}$ at longer wavelengths ( $>500 \mathrm{~nm}$ ) (Figure 8 ).

According to the $Z_{90}$ test, only one station had potential influence of bottom reflectance on the above water $R_{\mathrm{rs}}$, located at the northern tip of the lagoon, where clear oligotrophic waters were dominant even at the shallowest station near the coast (station 28). At this station the local depth 
was $11 \mathrm{~m}$, whereas the first optical depth $\left(\sim 1 / K_{\mathrm{d}}\right)$ reached a maximum of $19 \mathrm{~m}$ at $490 \mathrm{~nm}$. Since this was a unique case for the stations sampled at CALIOPE 2, we decided to remove this station from our analysis for simplicity, and not deal (at this point) with more complex bottom effect processing for ocean colour retrievals (as done by Murakami and Dupouy [37]). The other more coastal stations were located near rivers and mining sites, which had more scattering and absorbing waters, and the first optical depth was always somewhat shallower than the bottom depth (e.g., $5 \mathrm{~m}$ for $1 / K_{d}(490)$ at station 14 with $11 \mathrm{~m}$ of bottom depth). The stations with deepest light penetration ( $29 \mathrm{~m}$ for the first optical depth at $490 \mathrm{~nm}$ ) were located outside of the lagoon at the shelf slope (>500 m).
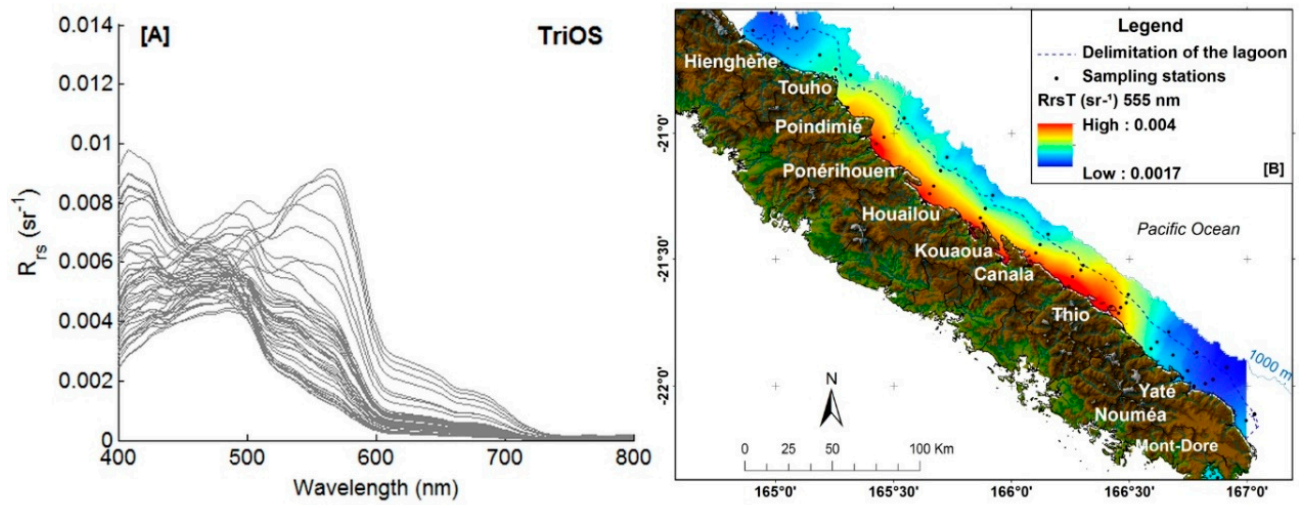

Figure 8. In situ remote sensing reflectance $\left(R_{\mathrm{rs}}\right)$ spectra obtained with the TriOS sensor $(\mathbf{A})$ and the surface distribution map of $R_{\mathrm{rs}}(555)$ (B) (Number of samples $=48$ ).

\subsubsection{Radiometric Comparisons}

The $R_{\mathrm{rs}} \mathrm{T}$ (TriOS) had a reasonably good agreement with $R_{\mathrm{rs}} \mathrm{S}$ (Satlantic), with an absolute percent difference between 8 to $20 \%$ at $412-555 \mathrm{~nm}$, and 12\% RPD for the $R_{\mathrm{rs}}(443: 555)$ ratio (Figure 9). This is within the expected uncertainty for in situ radiometric measurements, which can be somewhat higher than $10 \%$ especially under adverse environmental conditions i.e., partly cloudy skies, intensive winds, and within a high range of optical water types [14,15].
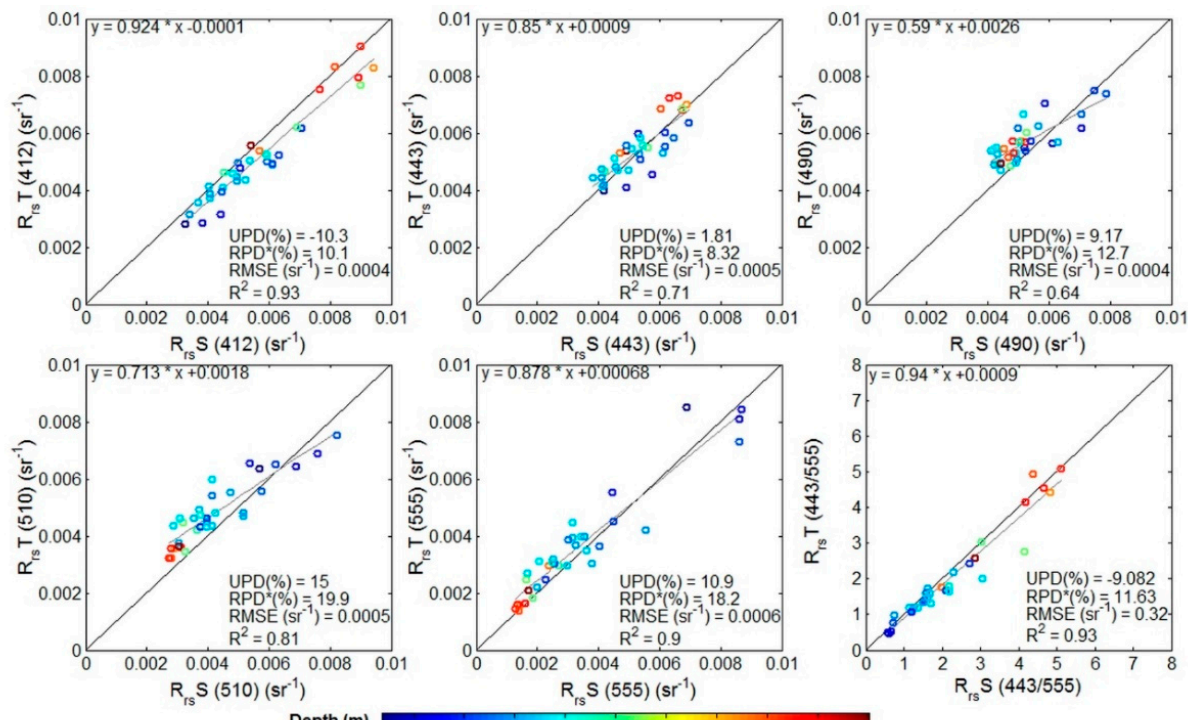

Figure 9. Comparison of Remote sensing reflectance from TriOS radiometer $\left(R_{\mathrm{rs}} \mathrm{T}\right)$ vs. Remote sensing reflectance from Satlantic radiometer $\left(R_{\mathrm{rS}} \mathrm{S}\right)$ for the ocean colour bands and the 443:555 ratio (Number of samples $=34$ ). 
The TriOS approach, with the PVC floating structure, yielded lower $R_{\mathrm{rs}}$ values compared with those of the free-falling profiler (Satlantic) especially at the blue bands (412-443 nm) ( -10 to $1.8 \mathrm{UPD}$ ) at the more coastal and shallow stations $\left(<25 \mathrm{~m}\right.$ ) (Figure 9). The negative $R_{\mathrm{rs}}$ bias could be explained by light attenuation at the very surface (from 0 to $2 \mathrm{~cm}$ ) [64] and self-shading effects [76], that are both more problematic for the shorter bands at highly absorbing waters. The $R_{\mathrm{rs}}(443)$ bias was in fact correlated to surface water turbidity with a correlation coefficient $r_{\mathrm{S}}, 0.53$. The floating PVC structure allowed the TriOS sensor to obtain $L_{\mathrm{u}}$ measurements up to $15 \mathrm{~m}$ away from the vessel, avoiding even greater shading effects from the platform $[15,63]$. Nonetheless, the PVC structure, as well as the instrument itself, can still cause some potential shading.

The $R_{\mathrm{rs}} \mathrm{T}$ at the green bands (510-555 nm), on the other hand, had more positive biases (15 to $11 \mathrm{UPD})$, compared to $R_{\mathrm{rs}} \mathrm{S}$, especially at the deeper stations ( $\left.>40 \mathrm{~m}\right)$, in the outer reaches of the lagoon (Figure 9). These positive biases were somewhat positively correlated to wind speed $\left(r_{\mathrm{s}}, 0.31\right)$, and negatively correlated to water turbidity $\left(r_{\mathrm{s}},-0.35\right)$. The overestimation of $R_{\mathrm{rs}}(555)$ at clearer waters, under intensive winds, could be explained by sub-surface bubble cloud effects. Bubble clouds generated by breaking waves under rough sea conditions (wind speed $>7.5 \mathrm{~m} \cdot \mathrm{s}^{-1}$ ), can increase $R_{\mathrm{rs}}$ to more than $10 \%$, especially at yellow-green bands, in clear waters [77]. Since the TriOS in-water sensor sampled $L_{\mathfrak{u}}$ measurements at the very surface $(\sim 2 \mathrm{~cm})$, whereas the Satlantic profiler sampled at depths from 2-15 m, the TriOS approach was likely much more influenced by sub-surface bubble clouds. As most of the stations of the CALIOPE 2 campaign were sampled under strong winds $\left(>8.5 \mathrm{~m} \cdot \mathrm{s}^{-1}\right)$, bubble cloud was a potential source of uncertainty for the in-water radiometric measurements. Another source of positive biases that could be associated to the TriOS approach is the potential additive signal of light reflection from the PVC structure on the in-water $L_{\mathrm{u}}(\lambda)$.

Both the negative $R_{\mathrm{rs}}(443)$ biases (at the coastal stations), and the positive $R_{\mathrm{rs}}(555)$ biases (at the deeper stations), contributed for the overall negative biases of the $R_{\mathrm{rs}} \mathrm{T}(443 / 555)$ ratio ( $-9 \%$ UPD). The impact of these spectrally uncorrelated biases on ocean colour retrievals, if applied a bio-optical algorithm, would be to overestimate the IOPs (and Chla), especially at the deeper stations with clearest waters, where the biases were larger (Figure 9).

Some other sources of uncertainty of the TriOS approach could be related to mismatches of the illumination condition over the in-water and deck sensors under a fast-changing sky, i.e., partially cloudy. This source, however, should add noise to the dispersion rather than characterize a "systematic" bias. Other sources of uncertainty are also related to the Satlantic free-falling profiler approach, including the use of deeper $L_{\mathrm{u}}$ and $E_{\mathrm{d}}$ measurements, which assumes a homogeneous water column with a constant diffuse attenuation coefficient [78]. Deeper $L_{\mathrm{u}}$ and $E_{\mathrm{d}}$ measurements with lower signal are also more subject to noise and difficult to extrapolate accurately to the surface. Furthermore, the roughened sea surface causes focus and defocusing effects by the wavy facets, which introduces noise to the in-water $E_{\mathrm{d}}$ measurements [79]. All these sources likely contributed to the noisy dispersion in the $R_{\mathrm{rs}}$ comparisons.

Even with all these sources of uncertainty, under mostly adverse environmental conditions, the blue to green $R_{\mathrm{rs}}$ bands and ratio matched reasonably well for the in-water approaches $(<20 \%$ RPD). The consistency of both methods revealed a good potential of the TriOS adapted approach (with the floating PVC structure) to obtain accurate in situ $R_{\mathrm{rs}}$. Previous works have shown systematic underestimation of the $R_{\mathrm{rs}}$ derived from TriOS (10 to more than $30 \%$ ) when winched beside a vessel, in respect to free-falling radiometers, due to strong shading effects from the platform $[14,63]$. Hence, the adapted TriOS in-water acquisition method appears more suitable, as the radiometer is launched away from the platform avoiding external perturbations on the measurements.

\subsubsection{Closure Experiment}

Since a greater number of stations were collected with the TriOS approach $(\mathrm{N}=48)$, we show only the results of the closure analysis using the $R_{\mathrm{rs}} \mathrm{T}$. The forward modelled $R_{\mathrm{rs}}(\mathrm{RTE})$, had a mean percent difference of 9 to $26 \%$ for the $443-555 \mathrm{~nm}$ bands and $20 \%$ for the $R_{\mathrm{rs}}(443 / 555)$ ratio, compared 
to the measured $R_{\mathrm{rs}} \mathrm{T}$ (Figure 10). Closure was not completely obtained even considering the effects of multiple scattering and variations in the $\beta$ on the bidirectional factor of the modelled $R_{\mathrm{rs}}$. Closure is always a challenge as there are uncertainties in both the measured and modelled $R_{\mathrm{rs}}$, and differences over than 30\% RPD could be expected across different water types and under adverse environmental [80-83]. Hence, the absolute differences below $20 \%$ point out a reasonably good consistency between the measured IOPs and RTE approximation with the measured $R_{\mathrm{rs}}$.

The $R_{\mathrm{rs}}$ RTE at $443 \mathrm{~nm}$ matched well the measurements, with both positive and negative biases ( $-1 \%$ UPD), whereas the $R_{\mathrm{rs}}$ RTE at the longer bands (490-555 nm) had an overall negative bias with -11 to $-19 \%$ UPD, leading to a positive bias for the $R_{\mathrm{rs}}(443 / 555)$ ratio (22\% UPD) (Figure 10). Some of these biases could be explained by the $R_{\mathrm{rs}} \mathrm{T}$ overestimation at the green bands, due to bubble cloud effects and structure in-water reflection. Comparing the $R_{\mathrm{rs}}$ RTE with $R_{\mathrm{rs}} \mathrm{S}$ the biases were somewhat lower, varying from 3 to $-6 \%$ UPD for the $443-555 \mathrm{~nm}$ bands, and 9\% UPD for the $R_{\mathrm{rs}}(443 / 555)$ ratio. This confirms the previous discussion, regarding the underestimation of the $R_{\mathrm{rs}}$ blue:green ratio by $R_{\mathrm{rs}} \mathrm{T}$, under influence of bubble clouds (and structure reflection) especially in clearer waters.

Regarding the modelled $R_{\mathrm{rs}}$, the sources of uncertainties are related to the approximation of the forward model, the environmental and bidirectional factors used and the measured IOPs. The differences between the environmental and bidirectional factors proposed by other works, i.e., obtained from Morel et al. [65] and Gordon et al. [29], were small ( $<5 \%)$. None of these factors, however consider variations in visibility and cloud cover, as this variability is more difficult to quantify for closure experiments, although it may cause significant differences between the modelled and measured $R_{\mathrm{rs}}$ [63]. Raman scattering is also neglected in these approximations and may account for $4-10 \%$ of the measured $R_{\mathrm{rs}}>490 \mathrm{~nm}$, in waters with Chla $0.1-0.5 \mathrm{mg} \cdot \mathrm{m}^{-3}$ [83]. Hence, this source may also explain some of the negative biases observed for the modelled $R_{\mathrm{rs}}>490 \mathrm{~nm}$, especially at the clearest waters. Uncertainties in the measured IOPs can also cause differences in these comparisons. The QFT-ICAM method with sample-specific beta factors (measured by PSICAM), should significantly reduce the $a_{\mathrm{p}}$ biases to less than 1\% [59]. However, challenges in the sample collection and manipulation may account for 10\% differences between triplicates. CDOM absorption measurements are also challenging especially in clear waters, which require the use of a long path length $(2 \mathrm{~m})$ using the UltraPath instrument. The long path length increases the signal, but also the probability of interference of small particles and colloids that may remain after the filtration [56], and differences in triplicates are also in order of $10 \%$. Although the water column was well-mixed during the CALIOPE 2 campaign, vertical stratification may also introduce some mismatches between the RTE approximations, which consider homogeneous profiles and use IOPs sampled at a fixed surface depth ( $2 \mathrm{~m}$ ) (with exception for $b_{\mathrm{bp}}$ ) and the measured $R_{\mathrm{rs}}$, representative of the integrated first optical depth.

All these sources of uncertainty contributed for the dispersion in the comparisons, and biases between the modelled and measured $R_{\mathrm{rs}}$. For the coastal stations, the spectral biases were, however, more correlated, and reduced when applying the blue:green $R_{\mathrm{rs}}$ ratio (Figure 10). Whereas, the deepest stations with the clearest waters, had more uncorrelated spectral biases which impacted more the $R_{\mathrm{rs}}(443: 555)$ comparison, probably mainly associated to the effects of bubble clouds and Raman scattering. Hence, these sources should also introduce some biases in the performance of the bio-optical algorithms, likely with overestimation of the retrieved Chl $a$ and IOPs. 

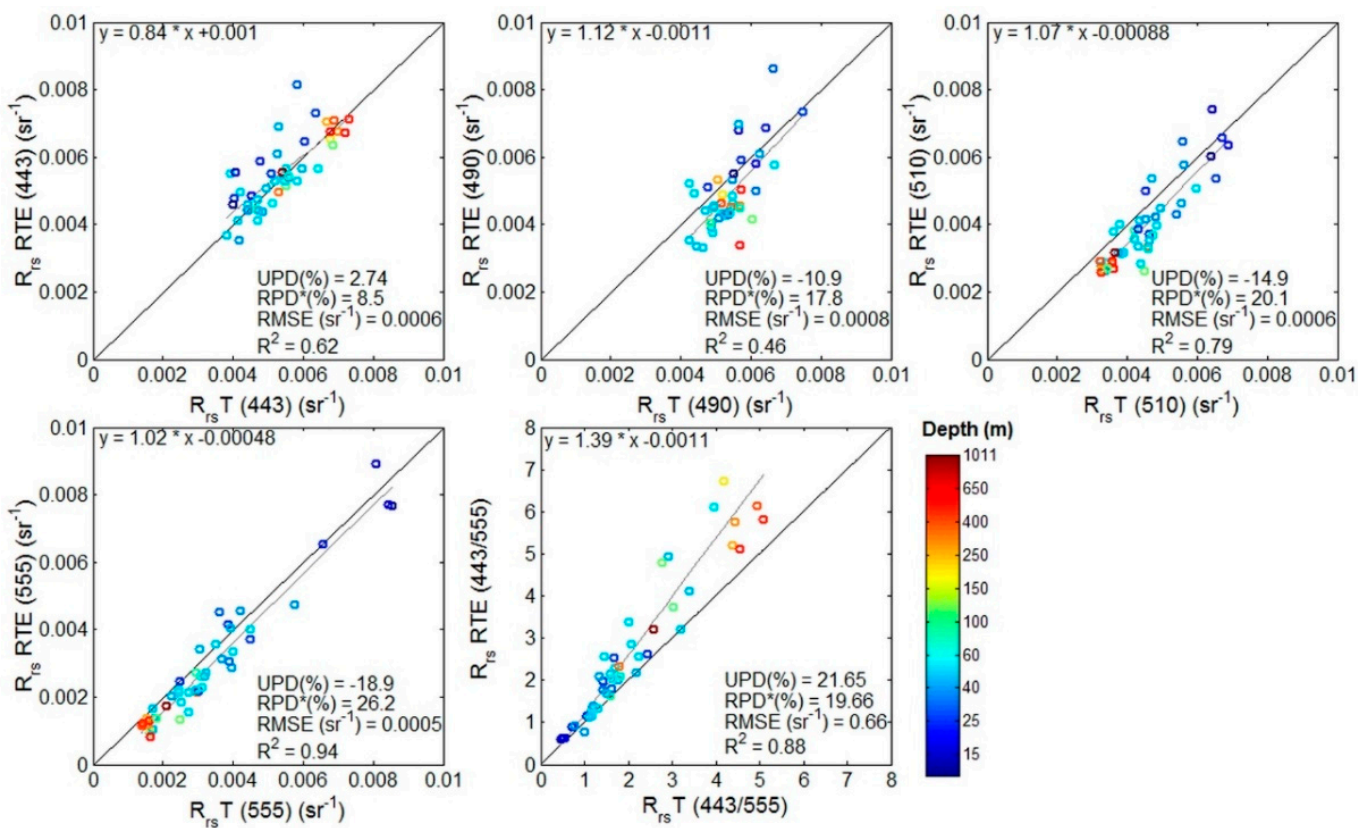

Figure 10. Comparison of the modelled Remote sensing reflectance $\left(R_{\mathrm{rs}}\right)$ of the radiative-transfer equation (RTE) following Park and Ruddick [66] and measured Remote sensing reflectance from TriOS radiometer $\left(R_{\mathrm{rs}} \mathrm{T}\right)$ for each band and for the 443:555 band ratio (Number of samples $=48$ ).

\subsection{Bio-Optical Algorithm Evaluation}

\subsubsection{Chlorophyll $a$ Concentration}

The empirical and semi-analytical ocean colour algorithms showed similar performance for the Chla retrievals at the ELNC during CALIOPE 2 (with $R_{\mathrm{rs}} \mathrm{T}$ ), i.e., a positive slope (3-6) $\sim 0.40 \mathrm{R}^{2}$, and a tendency of underestimation at the deeper stations and overestimation at the coastal stations (Figure 11). Taking out the stations with highest surface water turbidity ( 1 NTU) and contributions of $a_{\mathrm{dg}}$ to the total non-water absorption at $443 \mathrm{~nm}(>80 \%)$ (Stations 14, 20, 24 and 37), the overall performance for all the algorithms increased significantly, with RPD diminishing from 64 to $35 \%$ for GSM01 $\left(0.64 \mathrm{R}^{2}\right), 182$ to $122 \%$ RPD for GIOP $\left(0.70 \mathrm{R}^{2}\right)$, and 112 to $68 \%$ RPD for OC3M and OC4 $\left(\mathrm{R}^{2}=0.54\right)$. 


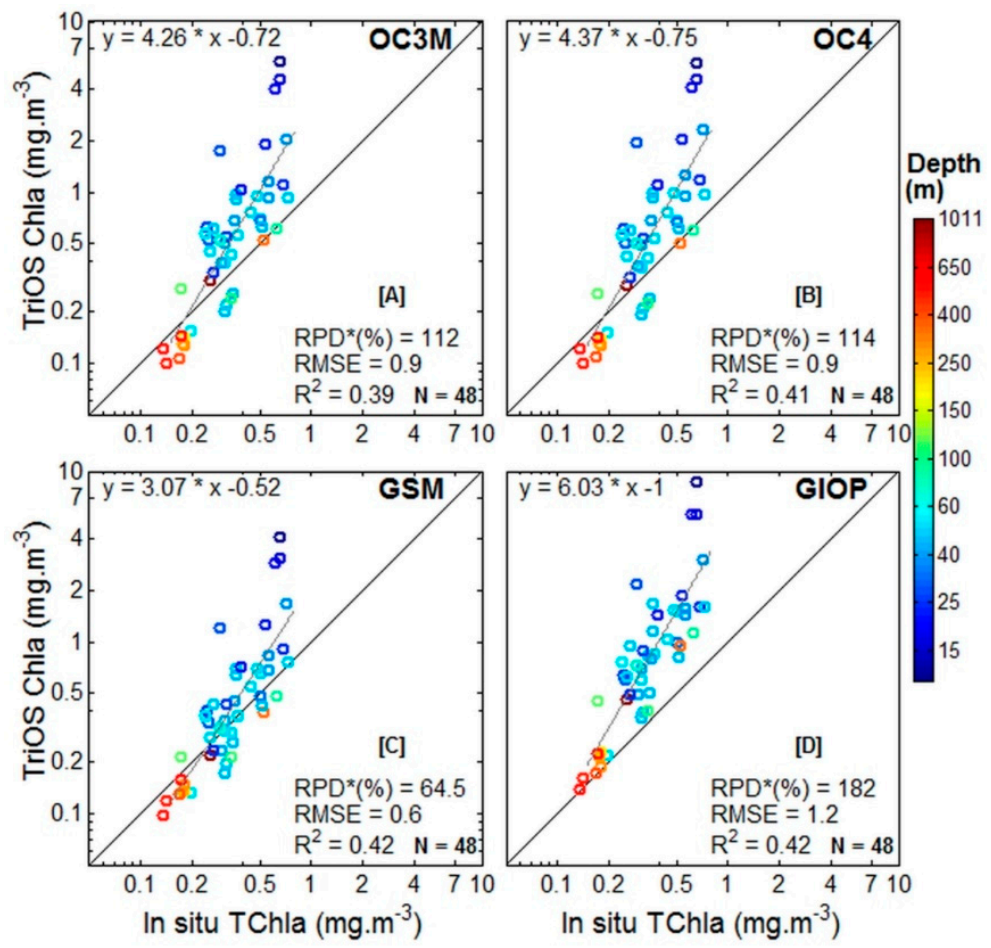

Figure 11. Comparisons between the in situ measured and modelled chlorophyll $a$ concentration (Chla) using Remote sensing reflectance from TriOS radiometer $\left(R_{\mathrm{rs}} \mathrm{T}\right)$ (TriOS Chla), determined with the: OC3M (A), OC4 (B), Garver-Siegel-Maritorena (GSM01) (C) and Generalized IOP (GIOP) (D) (Number of samples $=48$ ). Axes in log scale.

Overestimation of the Chla at turbid coastal waters is expected, especially for the empirical algorithms [12]. The surface water turbidity of the ELNC waters during the CALIOPE 2 campaign was not that high $(<1.09 \mathrm{NTU})$, but as shown in the previous section of bio-optical characterization, there was a complex mixture of the IOPs, with an important contribution of NAP and CDOM to the total non-water light absorption at $443 \mathrm{~nm}$ (maximum, 85\%). As the GSM01 semi-analytical approach separates the $a_{\mathrm{dg}}$ and $a_{\mathrm{phy}}$ contributions from the total absorption in the inversion scheme, it showed a better performance for the Chla retrieval at the coastal stations compared with the empirical algorithms. There were, however, still some high positive biases at the most turbid stations for the semi-analytical approaches (GSM and GIOP), due to the higher challenges to separate the $a_{\text {phy }}$ and $a_{\mathrm{dg}}$ terms at these stations in the inversion scheme (Figure 11).

Another important source of uncertainty in the Chla retrievals is regarding regional and local variations in the phytoplankton specific absorption coefficient, due to changes in community structure and photo-adaptation processes $[84,85]$. As shown in the bio-optical characterization section, the ELNC waters had $a_{\text {phy }}{ }^{*}(443)$ values mostly lower than expected for the corresponding Chla, according to the global relation [23] (see Figure 4). Hence, the Chla underestimations, at the deepest stations $\left(>50 \mathrm{~m}\right.$ ) by the OC3 and OC4 empirical algorithms were likely associated to the lower in situ $a_{\text {phy }}{ }^{*}(443)$ (mean, $0.049 \mathrm{~m}^{2} \mathrm{mgChl} a^{-1}$ ), compared to the expected values for the corresponding Chla (mean, $0.067 \mathrm{~m}^{2} \cdot \mathrm{mgChl}^{-1}$ ) [23]. Even the optimized global mean used for the GSM01 parameterization $\left(0.055 \mathrm{~m}^{2} \cdot \mathrm{mgChl}^{-1}\right)[28]$ was somewhat higher than the in situ $a_{\mathrm{phy}}{ }^{*}(443)$ at these stations, which likely caused some of the negative biases for the deeper stations (Figure 11).

Only the GIOP approach did not underestimate the Chla for the clearest waters (Figure 11), despite of the higher $a_{\text {phy }}{ }^{*}(443)$ used as input for the inversion scheme. The $a_{\text {phy }}{ }^{*}$ values used for the GIOP are obtained (by default) from the Bricaud et al. [23] global relation, using the Chla retrieved from OC4 (or OC3M) [32]. Hence, the $a_{\text {phy }}{ }^{*}(443)$ values used for the GIOP inversion at the deepest stations were even higher (mean, $0.07 \mathrm{~m}^{2} \cdot \mathrm{mgChl} a^{-1}$ ) than the GSM01 global mean, deviating even more from the 
in situ values. In this case, however, the apparent better performance of the GIOP for the Chla in the clearest waters was likely due to spectral compensation effects while inverting the other IOPs i.e., $a_{\mathrm{dg}}$ and $b_{\mathrm{bp}}$. As will be further shown, the $b_{\mathrm{bp}}(443)$ of the GIOP, for instance, was overestimated at the deepest stations, likely compensating for the $a_{\text {phy }}{ }^{*}(443)$ overestimation. Different parameterizations used for each of the specific IOPs have impacts on the inversion of all the IOPs due to such spectral compensation effects [84].

For the coastal stations, on the other hand, the GIOP had the highest positive Chla biases, likely due to the spectral mixture of $a_{\text {phy }}(443)$ and $a_{\mathrm{dg}}(443)$, as well as the $a_{\text {phy }}{ }^{*}(443)$ underestimations, in this case. Since the OC4 overestimated the Chl $a$ at these stations, the $a_{\text {phy }}{ }^{*}(443)$ obtained for the GIOP inversion, was even lower (mean, $0.037 \mathrm{~m}^{2} \cdot \mathrm{mgChl} a^{-1}$ ) than the in situ values (mean, $\left.0.048 \mathrm{~m}^{2} \cdot \mathrm{mgChl} a^{-1}\right)$. Although the GIOP parameterization scheme is more flexible than the GSM01, attempting to account for the $a_{\text {phy }}{ }^{*}(443)$ variability, local and regional variations that deviate from the global relation, is still not addressed. Moreover, uncertainties in the OC4 retrievals will propagate to the GIOP retrievals, which may explain the higher overestimations of the GIOP compared to the GSM for the coastal stations (Figure 11).

Since there were no positive biases (or only minor) at the deepest waters, the $R_{\mathrm{rs}} \mathrm{T}$ uncertainties had likely a minor impact on the Chla retrievals, or could even have minimized some of the underestimations, as pointed out in the previous sections. Using the $R_{\mathrm{rs}} \mathrm{S}$ as input, the overall performance of the algorithms was still very similar ( $<5 \%$ different).

Failures in the Chla determinations were thus mainly associated with the optical complexity of the lagoon, with a high spatial variability of non-algal particles and CDOM provided by different sources (rivers, corals and bottom resuspension), as well as the high variability of the specific IOPs. Wattelez et al. [46] adjusted an empirical algorithm with data collected at various campaigns in the southwest lagoon of New Caledonia, and coincident satellite MODIS-Aqua $R_{\text {rs, }}$ and obtained much better results than for the OC3M (with less than 30\% RMSE). Due to the optical complexity of the ELNC waters a regionally adjusted algorithm should also be tested using the entire data base collected during the different campaigns, and perhaps even including the data obtained at the western lagoon, for the development of a unique regional algorithm for New Caledonia.

\subsubsection{Inherent Optical Properties}

The semi-analytical algorithms have the advantage of inverting the IOPs i.e., $a_{\mathrm{phy}}, a_{\mathrm{dg}}$, and $b_{\mathrm{bp}}$, simultaneously or quasi-simultaneously, within some steps. Hence, for optically complex waters with mixture of different constituents that vary independently, from different sources, these approaches should be more suitable. The problem is that with a greater number of unknown parameters and variables, the solution also becomes more complex and subject to higher uncertainty, when each parameter is not appropriately adjusted. Hence, uncertainties in the parameterization of each of the specific IOPs will propagate to all the IOPs through spectral compensations effects. What differentiates each of the algorithms, besides of the mathematical approach of the inversion scheme, is how they deal with the parameterization of the specific IOPs, either by setting an optimized average i.e., GSM and LMI, or using empirical functions to account for at least for some of the specific optical variability, i.e., GIOP and QAA.

For the $a_{\text {phy }}(443)$ inversion, the GSM01 and GIOP showed basically the same performance as for the Chla retrievals, and the sources of uncertainty are similar to those previously cited, i.e., spectral mixture with higher NAP and CDOM contributions at the coastal stations, $a_{\text {phy }}{ }^{*}$ variability, and spectral compensations effects with the bulk IOP inversion. The GSM had an overall percent difference of $75 \%$ with both under (at deeper stations) and over estimations (at coastal stations) of $a_{\text {phy }}(443)$, with a positive slope of $3.2, \mathrm{R}^{2}=0.33$ and $\mathrm{RMSE}=0.04 \mathrm{~m}^{-1}$ (Figure 12). The GIOP overestimated $a_{\text {phy }}(443)$ at all of the stations with $114 \%$ RPD, 2.3 slope, $\mathrm{R}^{2}=0.39$ and $\mathrm{RMSE}=0.02 \mathrm{~m}^{-1}$. 

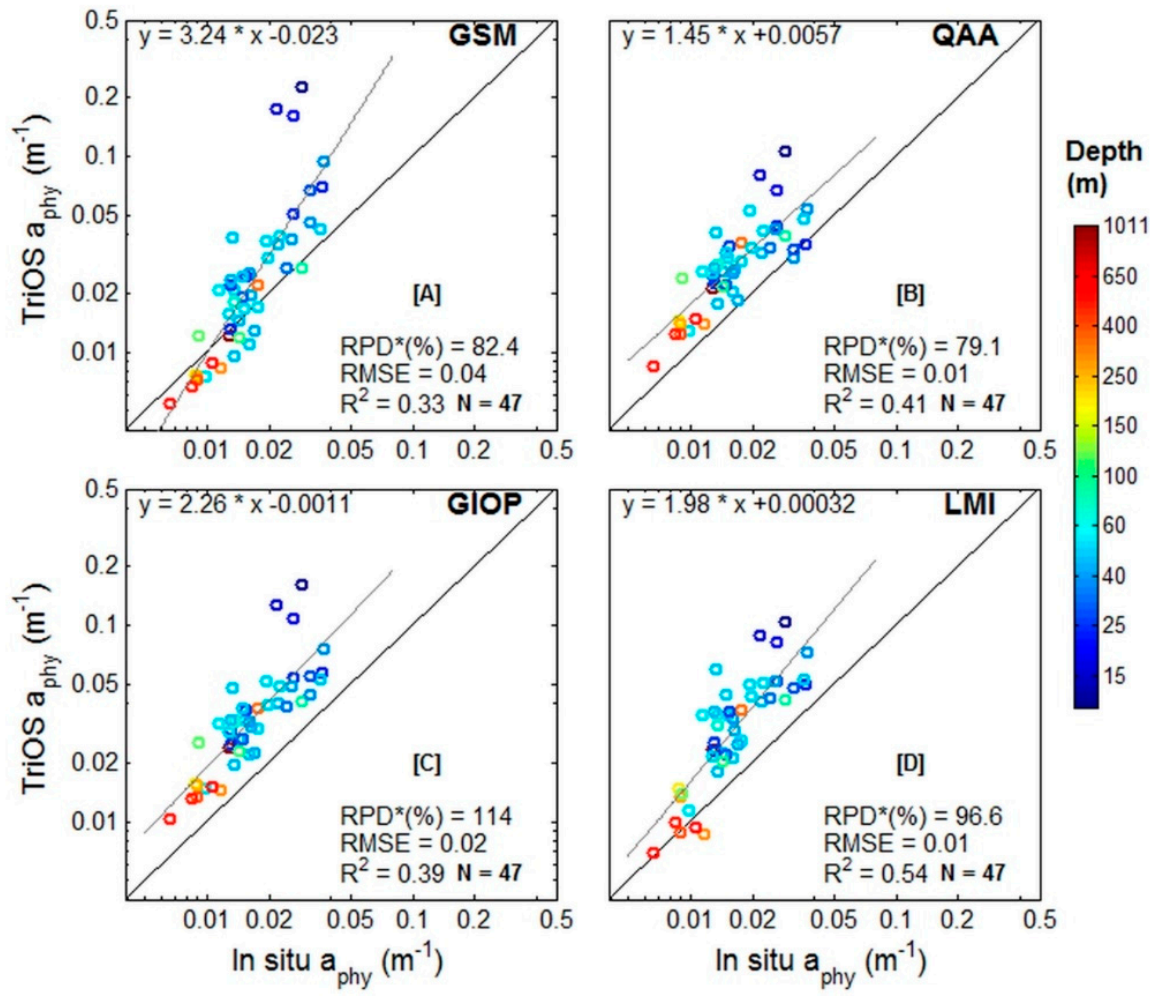

Figure 12. Comparisons between the in situ measured and modelled phytoplankton absorption $\left(a_{\text {phy }}\right)$ at $443 \mathrm{~nm}$ using Remote sensing reflectance from TriOS radiometer $\left(R_{\mathrm{rs}} \mathrm{T}\right)$ (TriOS $a_{\text {phy }}$ ) obtained with: Garver-Siegel-Maritorena (GSM01) (A), Quasi-Analytical Algorithm (QAA) (B), Generalized IOP (GIOP) (C) and Linear Matrix Inversion (LMI) (D) (Number of samples =47). Axes in log scale.

The QAA retrievals showed a similar dispersion as the GIOP $a_{\text {phy }}(443)$, as both approaches use the same parameterization for some specific IOPs, $\left(S_{\mathrm{dg}}\right.$ and $\left.S_{\mathrm{bbp}}\right)[30,32]$. However, the QAA had somewhat better retrievals for the coastal stations, resulting in a lower overall percent difference with $79 \%$, RMSE $=0.01 \mathrm{~m}^{-1}, \mathrm{R}^{2}=0.41$ and a slope of 1.45 (Figure 12). The QAAv5 is in fact adjusted for application to a wide range optical water types from oceanic to coastal waters, as it uses not only blue and green $R_{\mathrm{rs}}$ bands, but also red bands in the parameterization and inversion scheme. All of the QAA spectral parameters, including the $a_{\text {phy }}(443)$, are empirically derived using a blue:green $R_{\text {rs }}$ band ratio for each inversion [30], which may have also contributed for the improved $a_{\text {phy }}(443)$ retrievals, although local variations in $a_{\text {phy }}{ }^{*}$ and spectral mixture of NAP and CDOM still posed some challenges.

The LMI $a_{\text {phy }}(443)$ retrievals had a distribution similar to the QAA retrievals (with a lower slope of 1.98), but a higher mean percent difference (97\%). There was a good agreement for the deepest stations, and overestimations for the coastal stations. The regional adjustment uses an average $a_{\text {phy }}{ }^{*}(443)$ of $0.05 \mathrm{~m}^{2} \cdot \mathrm{mgChl} a^{-1}$, due to the dominance of nanoplankton cells in the New Caledonia coastal lagoons $[36,37]$. This value was very close to the in situ measurements obtained for the deeper stations, which may explain the best fit in this case, but was somewhat higher than the $a_{\text {phy }}{ }^{*}(443)$ of the coastal stations. The positive biases, in this case, could be due to the higher spectral mixture and overestimation of the other IOPs (such as $b_{\mathrm{bp}}(443)$ ), as will be further shown).

As for the Chl $a$ retrievals, the stations with highest $a_{\text {phy }}(443)$ biases for all algorithms (>100\% RPD) were the ones in which $a_{\mathrm{dg}}(443)$ contributed to more than $80 \%$ of the total non-water light absorption. Taking out these stations the overall biases reduces to $40 \%$ for the GSM, $60 \%$ for the QAA and, $70 \%$ for the LMI.

The optical dominance of NAP and CDOM absorption in the ELNC waters, on the other hand, favoured the retrieval of $a_{\mathrm{dg}}(443)$ by all algorithms, yielding the lowest percent differences i.e., $17-34 \%$ 
(Figure 13). The GSM01 retrievals had a similar distribution as the LMI (1.27 and 1.17 slope), as both algorithms use a $a_{\mathrm{dg}}$ spectral slope of $0.020 \mathrm{~nm}^{-1}$. The in situ measurements, however, showed a lower average $a_{\mathrm{dg}}$ spectral slope of $0.014 \mathrm{~nm}^{-1}$, which may partly explain the negative biases.
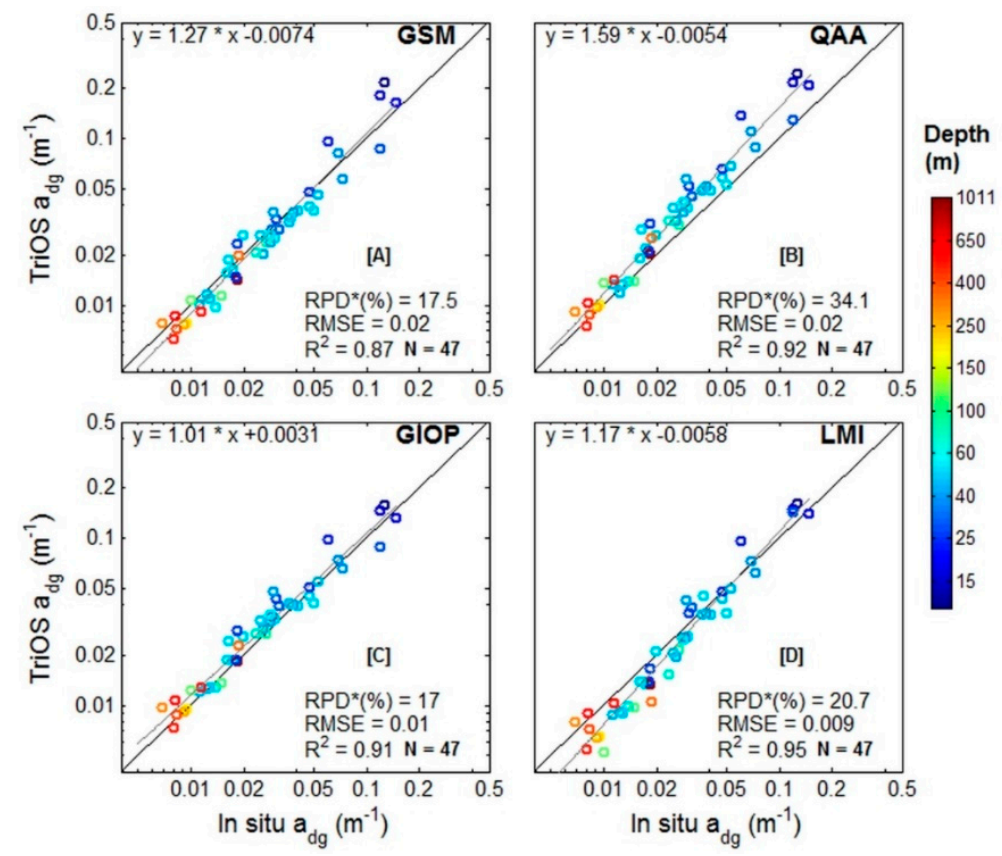

Figure 13. Comparisons between the in situ measured and modelled absorption of Coloured dissolved organic matter (CDOM) plus non-algal particles (NAP), the $a_{\mathrm{dg}}$ at $443 \mathrm{~nm}$ using Remote sensing reflectance from TriOS radiometer $\left(R_{\mathrm{rs}} \mathrm{T}\right)$ (TriOS $a_{\mathrm{dg}}$ ) obtained with: Garver-Siegel-Maritorena (GSM01) (A), Quasi-Analytical Algorithm (QAA) (B), Generalized IOP (GIOP) (C) and Linear Matrix Inversion (LMI) (D) (Number of samples $=47$ ). Axes in log scale.

The GIOP (by default) and QAA, both use the $a_{\mathrm{dg}}$ spectral slope obtained by an empirical relation with the blue:green $R_{\mathrm{rs}}$ band ratio for each station [32]. In this case, the values used for these algorithms were much closer to the in situ measurements i.e., $0.015-0.020 \mathrm{~nm}^{-1}$, with a mean of $0.016 \mathrm{~nm}^{-1}$. Lower $S_{\mathrm{dg}}$ used to invert $a_{\mathrm{dg}}(443)$ may, however, have favoured some of the positive biases due to the imprecise parameterization of the other specific IOPs, during the bulk inversion. It is worth noting here, that even though there were some deviations between the parameterized $S_{\mathrm{dg}}$ and in situ measurements, especially for the GSM01 and LMI, uncertainties due to local variations in this specific IOP, seemed to have minor impacts on the retrieved $a_{\mathrm{dg}}(443)$.

For the $b_{\mathrm{bp}}(443)$ inversion, the GSM01 and LMI gave the best performance with the lowest percent differences i.e., $\sim 40 \%$, and high covariation $\left(0.8-0.9 \mathrm{R}^{2}\right)$. The GIOP and QAA retrievals showed similar distributions with higher overestimations at the deepest stations, and an overall percent difference of $69 \%$ and $99 \%$, respectively (Figure 14). All the algorithms were mostly positively biased, which may be somewhat due to the higher $b_{\mathrm{bp}}$ spectral slope used to parameterize each of them. The GSM01 uses a global optimized $b_{\mathrm{bp}}$ spectral slope of $1.03 \mathrm{~nm}^{-1}$ and regional LMI of $1.0 \mathrm{~nm}^{-1}$, which were somewhat higher than the in situ measurements (mean, $0.07 \mathrm{~nm}^{-1}$ ). The GIOP (by default) and QAA both use an empirical function relating $R_{\mathrm{rs}}$ band ratios to estimate $S_{\mathrm{bbp}}$ [32]. In this case, however, the retrieved values were even higher than the in situ measurements, with an average of $1.38 \mathrm{~nm}^{-1}$. This may explain the higher positive biases obtained for these two approaches.

Besides of the biases related to imprecise parameterization of $S_{\mathrm{bbp}}$ and spectral compensation effects within the inversion process, the $b_{\mathrm{bp}}(443)$ retrievals are more impacted by slight variations in the $R_{\mathrm{rs}}$ at the longer bands. Hence, part of the positive biases could be related to the $R_{\mathrm{rs}} \mathrm{T}(555)$ positive biases due to bubble cloud effects, in-water structure reflection, as well as Raman scattering, 
as discussed in Section 3.2.2. Inversion algorithms that do not take into account Raman scattering, can have up to $50 \%$ positive biases for the $b_{\mathrm{bp}}(443)$ retrievals in waters with $0.1-0.5 \mathrm{mg} \cdot \mathrm{m}^{-3}$ of Chla [83].
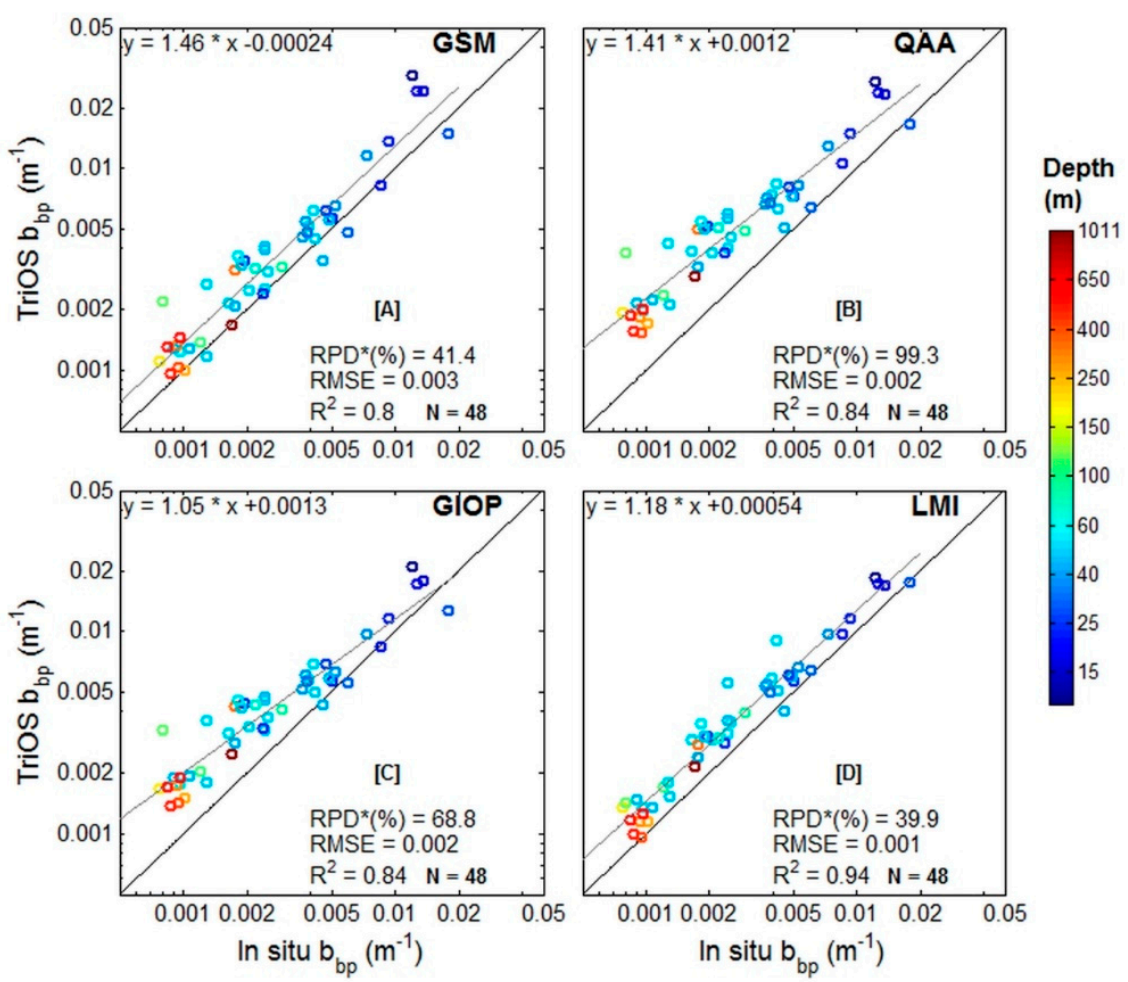

Figure 14. Comparisons between the in situ measured and modelled particle backscattering coefficient $\left(b_{\mathrm{bp}}\right)$ at $443 \mathrm{~nm}$ using Remote sensing reflectance from TriOS radiometer $\left(R_{\mathrm{rs}} \mathrm{T}\right)$ (TriOS $\left.b_{\mathrm{bp}}\right)$ obtained with: Garver-Siegel-Maritorena (GSM01) (A), Quasi-Analytical Algorithm (QAA) (B), Generalized IOP (GIOP) (C) and Linear Matrix Inversion (LMI) (D) (Number of samples $=47$ ). Axes in log scale.

In summary, all algorithms need improvements to properly invert the $a_{\mathrm{phy}}(443)$ (and Chla) in the ELNC, but they all showed a good performance for $a_{\mathrm{dg}}(443)$ and reasonable agreement for $b_{\mathrm{bp}}(443)$, especially GSM01 and LMI. The GSM01 and LMI algorithms provided very similar performance due to the close values used for the global and regional parameterizations of the specific IOPs. The GIOP and QAA, despite the more versatile parameterization scheme applicable to a wide range of optical water types, had some significant deviations, due to more complex regional-local variability of the specific optical properties at the ELNC. As discussed by Mukarami and Dupouy [37], due to the relatively high spatial-temporal variability of the specific IOPs at the ELNC waters, improvements in the inversion of the IOPs may potentially be achieved by applying an optical water type parameterization scheme rather than an average regional parameterization.

\subsubsection{Water Turbidity}

For surface water turbidity the three approaches that were applied to the ELNC i.e., the regional and global empirical algorithms of Ouillon et al. [38] and the single semi-analytical algorithm of Dogliotti et al. [39], showed a reasonable performance for optically deep waters (i.e., without bottom influence), with the RPD around 30\%, and a high co-variation between estimated and measured turbidity $\left(R^{2} \sim 0.92\right)$ (Figure 15). The regional algorithm adjusted for New Caledonia coastal waters (Figure 15A) had positive biases for the clearest waters and negative biases for turbidity above 0.2 NTU (slope, 0.58 ). The positive biases were obtained for the values out of the algorithm range of applicability, since the lowest turbidity used to calibrate the algorithm was 0.2 FTU [38]. This a limitation of purely empirical approaches which cannot deal with values out of their range of applicability. Above 0.2 NTU, 
the underestimation was rather systematic error, which is typical of measurement biases. As the regional approach uses a one-band empirical relation between $R_{\mathrm{rs}}(565)$ and water turbidity $(<1$ FTU), it can be highly influenced by biases in the remote sensing reflectance. Hence, differences in the $R_{\mathrm{rs}}$ used to calibrate and apply the algorithm can significantly impact the performance of this approach. Ouillon et al. [38] obtained the in situ $R_{\text {rs }}$ with above-water instrumentation (Ocean Optics USB2000), using a surface reflectance factor [86] to correct for the contribution of skylight radiance reflected from the ocean surface. These measurements however, are known to have residual uncorrected sky and sun glint signals manifested by a positive (approximately white) spectral shift $[14,61]$. This positive bias in the above-water $R_{\mathrm{rs}}$ can be corrected using simple white offset corrections for waters where null near-medium-infrared water reflectance can be assumed [61], or using more elaborated correction schemes for turbid waters [87]. Such residual correction was not performed by Ouillon et al. [38], which may explain the negative biases of the algorithm when applying $R_{\mathrm{rs}}$ obtained by in-water approaches as for the ELNC in the present work.
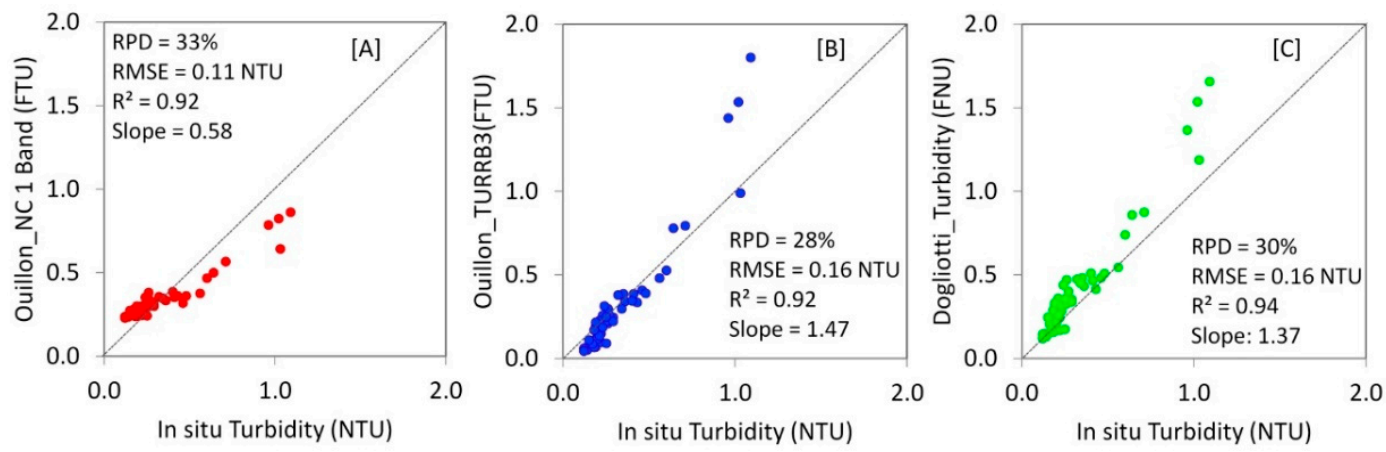

Figure 15. Turbidity estimated following Ouillon et al. [38] for New Caledonia (A) and "global" tropical coastal waters (B) and Dogliotti et al. [39] (C), compared to turbidity measured in situ (Number of samples $=48)$.

The global empirical algorithm developed by Ouillon et al. [38] for tropical coastal waters uses a two-step scheme with a 3-band ratio algorithm $\left(R_{\mathrm{rs}}(620)\right.$. $\left.R_{\mathrm{rs}}(681) / R_{\mathrm{rs}}(412)\right)$ to estimate turbidity below 1 FTU, and a one-band algorithm $\left(R_{\mathrm{rs}}(618)\right)$ for turbidity from 1 to 25 FTU. All of the ELNC cases fell into the 3-band ratio algorithm criteria and had a different distribution than the regional algorithm (Figure 15A,B). For the cases below the range of applicability $(<0.2$ NTU), the global algorithm underestimated the water turbidity, and for most of the cases between 0.2 and 1 FTU the global algorithm had an improved performance compared to the regional approach. This is because the band ratio of the global approach minimizes spectrally correlated biases related to the $R_{\mathrm{rs}}$. The drawback is that the selected band ratio is sensitive to changes in the particle composition, as well as dissolved absorbing constituents, i.e., CDOM, which impact the $R_{\mathrm{rs}}(412)$. Hence, higher absorption of CDOM and NAP, due to a higher fraction of organic compounds in the particle assemblage, will cause turbidity overestimations for this approach. This may explain the high overestimations obtained for the 3 stations that deviated more than 50\% (stations 14, 20 and 24, Figure 15B). These stations were located near rivers and mining sites, and the presence of dissolved and adsorbed iron, leached from iron-rich ultramafic soils (in New Caledonia) [51], may have also contributed to the higher light absorption in the shorter bands and turbidity overestimation. If a smoothed transition between the application of Equations (1) and (2) was made, using a weighted average for instance, the retrieved turbidity would be much closer to the observed one, reducing RPD to $18 \%$ for these 3 stations. The use of $R_{\mathrm{rs}}(681)$ to estimate turbidity is however questionable, since this band is located near the chlorophyll $a$ in vivo fluorescence peak, and uncorrelated changes in phytoplankton fluorescence will affect the turbidity estimation. Although the 3-band approach provided the best results for Ouillon et al. [38], 
and showed a reasonably good performance for the ELNC, the applicability of this approach needs to be analysed with caution due to all these potential sources of uncertainty.

The Dogliotti et al. [39] single algorithm was proposed to solve or at least minimize these sources of uncertainty with a one-band semi-analytical algorithm for all water types i.e., $\rho(645)$ for 0-15 FNU and $\rho(859)$ for 15-1000 FNU. In fact, even being parameterized with data collected from various sites, including a wide range of optical water types, the overall performance of this approach was reasonably good and similar to the Ouillon et al. [38] empirical algorithm for tropical waters ( $<25$ FTU), i.e., 30\% RPD, 0.16 FNU RMSE, $0.94 \mathrm{R}^{2}$ and 1.37 slope (Figure 15C). The semi-analytical approach improved the retrievals for the clearest waters ( $>0.2 \mathrm{NTU})$ and had an overall tendency to overestimate turbidity. The positive biases in this case could be related to the positive biases in the $R_{\mathrm{rs}}$ used for the application, as the one-band approach is more sensitive to slight variations in $R_{\mathrm{rs}}$. As discussed in Section 3.2 the TriOS in-water measurements seemed to be more subjected to positive biases at the longer bands i.e., $24 \%$ positive bias of $R_{\mathrm{rs}} \mathrm{T}$ compared to $R_{\mathrm{rs}} \mathrm{S}$ at $645 \mathrm{~nm}$, likely due to bubble clouds and in-water reflection. Raman scattering may also play a role as a source of positive bias for turbidity retrievals in clear waters, as it affects $b_{\mathrm{bp}}$ retrievals in inversion algorithms [83].

Another important source of uncertainty is related to the turbidity measurements using different methods and instrumentation. Optical turbidity measurements that use a broad band and different scattering angles are more influenced by variations in the particle composition, and the relation between turbidity and $b_{\mathrm{bp}}$ can vary by a factor of 2 [88]. Other sources that may account for up to $10 \%$ of uncertainty in the turbidity algorithm are related to variations in the scattering phase function (SPF) and bidirectional effects on the $R_{\mathrm{rs}}$. These however, were likely minor for the ELNC since there is typically a lower variability in SPF for relatively clear waters, and nadir $R_{\mathrm{rs}}$ measurements are less subject to bidirectional effects [39]. Finally, vertical stratification can also be a source of uncertainty in the turbidity retrievals, especially for the coastal stations, which are typically more stratified. Considering all these possible sources of uncertainty and the low range of turbidity measured in the ELNC during CALIOPE 2 (0.1-1.09 NTU), the surface water turbidity was reasonably well retrieved by the tested algorithms, encouraging their application to satellite ocean monitoring of ELNC waters, without bottom influence, and/or with proper bottom reflectance corrections on the surface $R_{\mathrm{rs}}[36,37]$.

\section{Conclusions and Final Remarks}

The East Lagoon of New Caledonia, a tropical semi-enclosed lagoon surrounded by a coral reef barrier, has oligo-mesotrophic waters containing a variety of optically active constituents, i.e., phytoplankton, coloured dissolved organic matter, and organic and inorganic non-algal particles. These constituents vary in concentration and optical properties, with different contributing sources, i.e., oligotrophic oceanic water intrusions across the reef barrier (especially in the southern and northern tips), and continental drainage along the coast. CDOM and NAP have various sources, from small and medium river inputs, coastal erosion at mining sites, sediment re-suspension at shallower depths $(<20 \mathrm{~m})$, as well as releases from the coral reef ecosystem, besides the autochthonous sources from the phytoplankton community. These different sources provide a complex mixture of inherent optical properties for the ELNC waters, which vary spatially and temporally according to the seasons.

The average Chla (and maximum value) observed during CALIOPE 2, end of the austral summer of 2014 (i.e., mean, $0.37 \mathrm{mg} \cdot \mathrm{m}^{-3}$ and maximum $0.725 \mathrm{mg} \cdot \mathrm{m}^{-3}$ ), was somewhat higher than the observed during CALIOPE 1 (mean, $0.21 \mathrm{mg} \cdot \mathrm{m}^{-3}$ and maximum $0.6 \mathrm{mg} \cdot \mathrm{m}^{-3}$ ) in the dry and calm winter season of 2011, and lower than during the CALIOPE 3 (mean, $0.37 \mathrm{mg} \cdot \mathrm{m}^{-3}$ and maximum $3.51 \mathrm{mg} \cdot \mathrm{m}^{-3}$ ), summer of 2016, which was more influenced by the rainy season. Even with the late rainy season, there was still a relatively high amplitude of variability of the IOPs during CALIOPE 2 , which was also influenced by wind-induced resuspension processes, i.e., $0.007-0.037 \mathrm{~m}^{-1}$ for $a_{\text {phy }}(443), 0.001-0.10 \mathrm{~m}^{-1}$ for $a_{\text {nap }}(443), 0.004-0.037 \mathrm{~m}^{-1}$ for $a_{\text {cdom }}(443)$, and $0.004-0.018 \mathrm{~m}^{-1}$ for $b_{\mathrm{bp}}(443)$, associated to the concentration of the optical constituents from the different autochthonous and allochthonous contributing sources. There were also some important "local" variations in the 
specific optical properties. The phytoplankton specific absorption coefficient was generally lower than typical values observed for the corresponding Chla range across the oceans (mean, $0.049 \mathrm{~m}^{2} \cdot \mathrm{mgChl} a^{-1}$ ), likely due to photo-adaptation processes. The spectral slopes of $a_{\mathrm{dg}}$ (mean, $0.016 \mathrm{~nm}^{-1}$ ) and $b_{\mathrm{bp}}$ (mean, $0.07 \mathrm{~nm}^{-1}$ ) were also lower than global mean values used to parameterize semi-analytical ocean colour algorithms, likely due to the higher contributions of NAP, including inorganic sediments from iron-rich eroded soil due to the mining activities.

Ocean colour radiometric measurements by the in-water instruments were in reasonable agreement ( $<20 \%$ RPD for $R_{\mathrm{rs}}(412-555)$ ), despite the generally adverse environmental conditions of variable cloud cover, some high solar zenith angles, and relatively strong winds (mean speed: $8.5 \mathrm{~m}^{-1}$ ). An adapted floating PVC structure attached to the TriOS in-water sensor, allowed data collection away from the vessel to avoid platform shading effects, therefore improving the match-ups between $R_{\mathrm{rs}}(412-555)$ obtained by the free-falling Satlantic profiler. Minor uncertainties likely associated to self-shading effects, bubble clouds, and reflection by ship structures remained, especially for the TriOS approach, due to the range of optical water types and rough sea conditions sampled during CALIOPE 2 . These adverse conditions posed higher challenges for the closure experiment, but still differences were lower than those observed in other works ( $<26 \%$ RPD for $\left.R_{\mathrm{rs}}(443-555)\right)$, encouraging the use of the adapted TriOS in-water approach. A potential source of difference in the measured and modelled $R_{\mathrm{rs}}$ is also due to Raman scattering, which may explain some of the negative RTE $R_{\mathrm{rs}}$ biases. When applying the bio-optical algorithms the $R_{\mathrm{rs}} \mathrm{T}$ uncertainties should have caused higher impacts on the IOP retrievals at the clearest waters, with overestimations for all IOPs. Such impacts were minor for the Chla and absorption coefficients, as the positive biases were obtained mostly at the coastal turbid stations. For the $b_{\mathrm{bp}}(443)$ retrievals, however, positive $R_{\mathrm{rs}}$ biases and ignoring Raman scattering likely contributed to the positive $b_{\mathrm{bp}}$ biases obtained in all cases.

The GSM01 provided the best overall performance inverting the Chla and $a_{\text {phy }}(443)$ with $35 \%$ RPD, (excluding the most turbid coastal stations), the $a_{\mathrm{dg}}(443)$ with $18 \%$ RPD (for all cases), and the $b_{\mathrm{bp}}(443)$ with $40 \%$ RDP. For a globally tuned algorithm applied to a coastal lagoon, with optically complex waters, this algorithm performed reasonably well, and may be applied to monitor the ELNC waters, with caution only for the Chla and $a_{\text {phy }}(443)$ retrievals in the most turbid waters (>1 NTU) with higher spectral mixture. The QAA also provided reasonably good retrievals and was particularly better for the $a_{\text {phy }}(443)$ inversion at the coastal turbid stations. The GIOP and LMI showed potential for an improved performance if site-specific parameterizations for the $a_{\mathrm{phy}}{ }^{*}, S_{\mathrm{dg}}$, and $b_{\mathrm{bp}}$ spectral slopes are applied. The regionally tuned LMI, however, revealed the challenge of how to select the best parameterization, as the regional algorithm still did not properly capture spatiotemporal variations in the specific IOPs of the ELNC. An optical water type parameterization scheme could be an alternative and needs further investigation.

The global and regional water turbidity algorithms showed promising results for satellite ocean colour applications, with biases mostly related to the $R_{\mathrm{rs}}$ and turbidity measurements used for each adjustment, and particle type variability that may still leave some residual biases depending on the approach and methods used. The global single algorithm proposed by Dogliotti et al. [39] seems to be the most robust approach applicable for all water types, independent of the particle assemblage and for a wide range of turbidity ( $0-1000 \mathrm{FNU}$ ), if provided with high quality $R_{\mathrm{rs}}$ or $\rho$ values; it performed similarly to the Ouillon et al. [38] algorithm for tropical waters on the CALIOPE 2 data. Surface water turbidity is an important parameter to monitor in the ELNC, especially to analyse the impacts of river runoff after intensive rainy events and soil erosion at the mining sites [42], as the increased water turbidity can have severe consequences for the coral reef ecosystem.

Future works should gather all the data sets from the CALIOPE cruises across the ELNC, to fully characterize the spatial and temporal bio-optical variability under different scenarios (e.g., dry and wet seasons), and to build a robust database for appropriate parameterizations of the ocean colour algorithms (regional/seasonal or class-based). With proper parameterizations ocean colour 
products may then be used to monitor the biogeochemical properties at the ELNC and detect changes in this highly vulnerable marine ecosystem.

Author Contributions: Data curation, L.R.F., N.R., R.R., D.D., H.M. and C.D.; Formal analysis, L.R.F., N.R., R.R., H.M. and C.D.; Investigation, L.R.F., R.F., R.R., D.D. and C.D.; Supervision, N.R., M.K., R.F. and C.D.; Validation, L.R.F., N.R., R.F., R.R. and H.M.; Visualization, L.R.F. and N.R.; Writing-original draft, L.R.F., N.R. and M.K.; Writing-review \& editing, L.R.F., N.R., M.K., R.F., R.R., D.D., H.M. and C.D.

Funding: Funding for the cruise was provided by INSU EC2CO French National Program and Institut de Recherche pour le Développement (IRD) (to C. Dupouy), the Scripps Institution of Oceanography and the National Aeronautics and Space Administration (to R. Frouin), and the National Institute for Space Research (INPE) (to L.R. Favareto and M. Kampel). Luciane R. Favareto was supported by a fellowship from the Coordenação de Aperfeiçoamento de Pessoal de Nivel Superior (CAPES).

Acknowledgments: The authors thank all the participants of the CALIOPE 2 cruise involved in the data collection and analysis obtained in the frame of INSU-EC2CO project (TRansfErts de la Matière Organique dissoute coLOrée). The authors also acknowledge the administrative staff of the IRD Center of Nouméa, New Caledonia and the captain and crew of R/V Alis. The Government of New Caledonia and Southern and Northern Provinces of New Caledonia and Aires Coutumières et Mairies of the ELNC gave authorization to sample the eastern New Caledonia lagoon during the CALIOPE 2 cruise.

Conflicts of Interest: The authors declare no conflict of interest.

\section{Abbreviations}

$0^{-} \quad$ Just below the surface

$0^{+} \quad$ Just above the surface

$a_{\text {phy }}{ }^{*} \quad$ Phytoplankton absorption coefficient normalized by Chla, $\mathrm{m}^{2} / \mathrm{mg}$

$a_{\text {cdom }} \quad$ CDOM absorption coefficient, $\mathrm{m}^{-1}$

$a_{\mathrm{dg}} \quad$ Detritus absorption coefficient, $\mathrm{m}^{-1}$

$a_{\text {nap }} \quad$ Non-algal particulate absorption coefficient, $\mathrm{m}^{-1}$

$a_{\mathrm{p}} \quad$ Particulate absorption coefficient, $\mathrm{m}^{-1}$

$a_{\text {phy }} \quad$ Phytoplankton absorption coefficient, $\mathrm{m}^{-1}$

$a_{\mathrm{w}} \quad$ Pure seawater absorption coefficient, $\mathrm{m}^{-1}$

$b_{\mathrm{bp}} \quad$ Particulate backscattering coefficient, $\mathrm{m}^{-1}$

$b_{\mathrm{w}} \quad$ Pure seawater backscattering coefficient, $\mathrm{m}^{-1}$

CDOM Coloured dissolved organic matter

Chla Chlorophyll $a$ concentration, $\mathrm{mg} / \mathrm{m}^{3}$

$E_{\mathrm{d}} \quad$ Downwelling solar irradiance, $\mathrm{W} \cdot \mathrm{m}^{-1}$

ELNC Eastern Lagoon of New Caledonia

$K_{\mathrm{d}} \quad$ Diffuse attenuation coefficient, $\mathrm{m}^{-1}$

$L_{\mathrm{u}} \quad$ Upwelling radiance, $\mathrm{W} \cdot \mathrm{m}^{-2} \cdot \mathrm{sr}^{-1}$

$L_{\mathrm{W}} \quad$ Water leaving radiance, $\mathrm{W} \cdot \mathrm{m}^{-2} \cdot \mathrm{sr}^{-1}$

$\mathrm{R}^{2} \quad$ Coefficient of determination

$R_{\mathrm{rs}} \quad$ Remote sensing reflectance (just above surface), $\mathrm{sr}^{-1}$

$R_{\mathrm{rs}} \mathrm{S} \quad$ Remote sensing reflectance from Satlantic radiometer, $\mathrm{sr}^{-1}$

$R_{\mathrm{rs}} \mathrm{T} \quad$ Remote sensing reflectance from TriOS radiometer, $\mathrm{sr}^{-1}$

$S_{\mathrm{dg}} \quad$ Spectral slope of $a_{\mathrm{dg}}, \mathrm{nm}^{-1}$

$S_{\mathrm{bbp}} \quad$ Spectral slope of $b_{\mathrm{bp}}, \mathrm{nm}^{-1}$

$S_{\text {cdom }} \quad$ Spectral slope of $a_{\text {cdom }}, \mathrm{nm}^{-1}$

$S_{\text {nap }} \quad$ Spectral slope of $a_{\text {nap }}, \mathrm{nm}^{-1}$

$\beta \quad$ Volume scattering function, $\mathrm{m}^{-1} \mathrm{sr}^{-1}$

$\lambda \quad$ Wavelength, $\mathrm{nm}$ 


\section{References}

1. NOAA'S. Coral Reef Conservation Program: Coastal Protection. 2011. Available online: http:/ / coralreef. noaa.gov/aboutcorals/values/coastalprotection/ (accessed on 22 May 2014).

2. Payri, C.; Benzoni, F.; Houlbreque, F. Le blanchissement des coraux: L'épisode de 2016 en Nouvelle Calédonie. l'ENA hors les murs 2017, 470, 13-16.

3. Hoegh-Guldberg, O.; Mumby, P.J.; Hooten, A.J.; Steneck, R.S.; Greenfield, P.; Gomez, E.; Harvell, C.D.; Sale, P.F.; Edwards, A.J.; Caldeira, K.L.; et al. Coral reefs under rapid climate change and ocean acidification. Science 2007, 318, 1737-1742. [CrossRef] [PubMed]

4. Diaz-Pulido, G.; Gouezo, M.; Tilbrook, B.; Dove, S.; Anthony, K.R.N. High $\mathrm{CO}_{2}$ enhances the competitive strength of seaweeds over corals. Ecol. Lett. 2011, 14, 156-162. [CrossRef] [PubMed]

5. Courtial, L.; Ferrier-Pages, C.; Jaquet, S.; Houlbreque, F. Effects of temperature and UVR on organic matter fluxes and the metabolic activity of Acropora muricata. Biol. Open 2017, 6, 1190-1199. [CrossRef] [PubMed]

6. Andrefouët, S.; Payri, C.; Van Wynsberge, S.; Lauret, O.; Alefaio, S.; Preston, N.G.; Yamano, H.; Baudel, S. The timing and the scale of the proliferation of Sargassum polycystum in Funafuti Atoll, Tuvalu. J. Appl. Phycol. 2017, 29, 3097-3108. [CrossRef]

7. IUCN. The Lagoons of New Caledonia: Reef Diversity and Associated Ecosystems (France); Evaluation Report; World Heritage Committee IUCN: Gland, Switzerland, 2008; pp. 43-54.

8. Dupouy, C.; Lefèvre, J.; Wattelez, G.; Martias, C.; Andreoli, R.; Lille, D. Satellite survey of lagoons and reefs. In Récifs Calédoniens; IFRECOR: Roubaix, France, 2018.

9. Dupouy, C.; Röttgers, R.; Tedetti, M.; Martias, C.; Murakami, H.; Doxaran, D.; Lantoine, F.; Rodier, M.; Favareto, L.R.; Kampel, M.; et al. Influence of CDOM and particle composition on ocean color of the Eastern New Caledonia Lagoon during the CALIOPE cruises. In Ocean Remote Sensing and Monitoring from Space; 92610M; International Society for Optics and Photonics: Bellingham, WA, USA, 2014; Volume 9261. [CrossRef]

10. Martias, C.; Tedetti, M.; Lantoine, F.; Jamet, L.; Dupouy, C. Characterization and sources of colored dissolved organic matter in a coral reef ecosystem subject to ultramafic erosion pressure (New Caledonia, Southwest Pacific). Sci. Total Environ. 2018, 616-617, 438-452. [CrossRef] [PubMed]

11. Eakin, C.M.; Nim, C.J.; Brainard, R.E; Aubrecht, C.; Elvidge, C.; Gledhill, D.K.; Muller-Karger, F.; Mumby, P.J.; Skirving, W.J.; Strong, A.E.; et al. Monitoring coral reefs from space. Oceanography 2010, 23, 118-133. [CrossRef]

12. Mouw, C.B.; Greb, S.; Aurin, D.; DiGiacomo, P.M.; Lee, Z.; Twardowski, M.; Binding, C.; Hu, C.; Ma, R.; Moore, T.; et al. Aquatic color radiometry remote sensing of coastal and inland waters: Challenges and recommendations for future satellite missions. Remote Sens. Environ. 2015, 160, 15-30. [CrossRef]

13. Werdell, P.J.; Bailey, S.W. An improved in-situ bio-optical data set for ocean color algorithm development and satellite data product validation. Remote Sens. Environ. 2005, 98, 122-140. [CrossRef]

14. Toole, D.A.; Siegel, D.A.; Menzies, D.W.; Neumann, M.J.; Smith, R.C. Remote-sensing reflectance determinations in the coastal ocean environment: Impact of instrumental characteristics and environmental variability. Appl. Opt. 2000, 39, 456-469. [CrossRef] [PubMed]

15. Hooker, S.B.; Maritorena, S. An evaluation of oceanographic radiometers and deployment methodologies. J. Atmos. Ocean. Technol. 2000, 17, 811-830. [CrossRef]

16. Mitchell, B.G.; Kahru, M.; Wieland, J.; Stramska, M. Determination of spectral absorption coefficients of particles, dissolved material and phytoplankton for discrete water samples. In Ocean Optics Protocols for Satellite Ocean Color Sensor Validation, Revision 4; National Aeronautical and Space Administration, Goddard Space Flight Center, NASA: Greenbelt, MD, USA, 2003; Chapter 4; Volume 4, pp. 39-60.

17. Twardowski, M.S.; Claustre, H.; Freeman, S.A.; Stramski, D.; Huot, Y. Optical backscattering properties of the "clearest" natural waters. Biogeosciences 2007, 4, 1041-1058. [CrossRef]

18. Röttgers, R.; Doxaran, D.; Dupouy, C. Quantitative filter technique measurements of spectral light absorption by aquatic particles using a portable integrating cavity absorption meter (QFT-ICAM). Opt. Express 2016, 24, A1-A20. [CrossRef] [PubMed]

19. IOCCG. Remote Sensing of Inherent Optical Properties: Fundamentals, Tests of Algorithms, and Applications, 5th ed.; Reports of the International Ocean-Colour Coordinating Group: Dartmouth, NS, Canada, 2006; p. 124. 
20. Gitelson, A.A.; Schalles, J.F.; Hladik, C.M. Remote chlorophyll-a retrieval in turbid, productive estuaries: Chesapeake Bay case study. Remote Sens. Environ. 2007, 109, 464-472. [CrossRef]

21. Dall'Olmo, G.; Gitelson, A.A. Effect of bio-optical parameter variability on the remote estimation of chlorophyll-a concentration in turbid productive waters: Experimental results. Appl. Opt. 2005, 44, 412-422. [CrossRef] [PubMed]

22. O'Reilly, J.E.; Maritorena, S.; Siegel, D.A.; O’Brien, M.C.; Toole, D.; Mitchell, B.G.; Kahru, M.; Chavez, F.P.; Strutton, P.; Cota, G.F.; et al. Ocean color chlorophyll a algorithms for SeaWiFS, OC2, and OC4: Version 4. In SeaWiFS Postlaunch Technical Report Series; v.11; SeaWiFS Postlaunch Calibration and Validation Analyses, Part 3; Hooker, S.B., Firestone, E.R., Eds.; NASA, Goddard Space Flight Center: Greenbelt, MD, USA, 2000; pp. 9-23.

23. Bricaud, A.; Morel, A.; Babin, M.; Allali, K.; Claustre, H. Variations of light absorption by suspended particles with chlorophyll a concentration in oceanic (case 1) waters: Analysis and implications for bio-optical. J. Geophys. Res. 1998, 103, 31033-31044. [CrossRef]

24. Ciotti, A.M.; Lewis, M.R.; Cullen, J.J. Assessment of the relationships between dominant cell size in natural phytoplankton communities and the spectral shape of the absorption coefficient. Limnol. Oceanogr. 2002, 47, 404-417. [CrossRef]

25. Loisel, H.; Nicolas, J.M.; Sciandra, A.; Stramski, D.; Poteau, A. Spectral dependency of optical backscattering by marine particles from satellite remote sensing of the global ocean. J. Geophys. Res. 2006, 111, C09024. [CrossRef]

26. Siegel, D.A.; Maritorena, S.; Nelson, N.B. Global distribution and dynamics of colored dissolved and detrital organic materials. J. Geophys. Res. 2002, 107, 1-14. [CrossRef]

27. Garver, S.A.; Siegel, D.A. Inherent optical property inversion of ocean color spectra and its biogeochemical interpretation. I. Time series from the Sargasso Sea. J. Geophys. Res. 1997, 102, 18607-18625. [CrossRef]

28. Maritorena, S.; Siegel, D.A.; Peterson, A.R. Optimization of a semianalytical ocean color algorithm for global-scale applications. Appl. Opt. 2002, 41, 2705-2714. [CrossRef] [PubMed]

29. Gordon, H.R.; Brown, O.B.; Evans, R.H.; Brown, J.W.; Smith, R.C.; Baker, K.S.; Clark, D.K. A Semianalytic Radiance Algorithm of Ocean Color. J. Geophys. Res. 1988, 93, 10909-10924. [CrossRef]

30. Lee, Z.; Carder, K.L.; Arnone, R.A. Deriving inherent optical properties from water color: A multiband quasi-analytical algorithm for optically deep waters. Appl. Opt. 2002, 41, 5755-5772. [CrossRef] [PubMed]

31. Lee, Z.; Weidemann, A.; Kindle, J.; Arnone, R.; Carder, K.L.; Davis, C. Euphotic zone depth: Its derivation and implication to ocean-color remote sensing. J. Geophys. Res. 2007, 112, C03009. [CrossRef]

32. Werdell, P.J.; Franz, B.A.; Bailey, S.W.; Feldman, G.C.; Boss, E.; Brando, V.E.; Dowell, M.; Hirata, T.; Lavender, S.J.; Lee, Z.; et al. Generalized ocean color inversion algorithm for retrieving marine inherent optical properties. Appl. Opt. 2013, 52, 2019-2037. [CrossRef] [PubMed]

33. Hoge, F.E.; Lyon, P.E. Satellite retrieval of inherent optical properties by linear matrix inversion of oceanic radiance algorithms: An analysis of algorithm and radiance measurement errors. J. Geophys. Res. 1996, 101, 16631-16648. [CrossRef]

34. Hoge, F.E.; Lyon, P.E. Spectral parameters of inherent optical property models: Methods for satellite retrieval by matrix inversion of an oceanic radiance model. Appl. Opt. 1999, 38, 1657-1662. [CrossRef] [PubMed]

35. Lyon, P.; Hoge, F. The linear matrix inversion algorithm. In Remote Sensing of Inherent Optical Properties: Fundamentals, Tests of Algorithms, and Applications; IOCCG Report Number 5; Lee, Z., Ed.; International Ocean-Colour Coordinating Group (IOCCG): Monterey, CA, USA, 2006; Chapter 7; pp. 49-56.

36. Murakami, H.; Dupouy, C.; Roettgers, R.; Frouin, J.R. Estimation of inherent optical properties using in-situ hyperspectral radiometer and MODIS along the east coast of New Caledonia. In Remote Sensing of the Marine Environment II; SPIE: Bellingham, WA, USA, 2012. [CrossRef]

37. Murakami, H.; Dupouy, C. Atmospheric correction and inherent optical property estimation in the southwest New Caledonia lagoon using AVNIR-2 high-resolution data. Appl. Opt. 2013, 52, 182-198. [CrossRef] [PubMed]

38. Ouillon, S.; Douillet, P.; Petrenko, A.; Neveux, J.; Dupouy, C.; Froidefond, J.M.; Andréfouët, S.; Muñoz-Caravaca, A. Optical Algorithms at Satellite Wavelengths for Total Suspended Matter in Tropical Coastal Waters. Sensors 2008, 8, 4165-4185. [CrossRef] [PubMed] 
39. Dogliotti, A.; Ruddick, K.G.; Nechad, B.; Doxaran, D.; Knaeps, E. A single algorithm to retrieve turbidity from remotely sensed data in all coastal and estuarine waters. Remote Sens. Environ. 2015, 156, 157-168. [CrossRef]

40. Dupouy, C.; Savranski, T.; Lefevre, J.; Despinoy, M.; Mangeas, M.; Fuchs, R.; Faure, V.; Ouillon, S.; Petit, M. Monitoring Optical Properties of the Southwest Tropical Pacific. In Remote Sensing of the Coastal Ocean, Land, and Atmosphere Environment; Frouin, R.J., Yoo, H.R., Won, J.-S., Feng, A., Eds.; SPIE: Bellingham WA, USA, 2010; Volume 7858, p. 14. [CrossRef]

41. Dupouy, C.; Neveux, J.; Ouillon, S.; Frouin, R.; Murakami, H.; Hochard, S.; Dirberg, G. Inherent optical properties and satellite retrieval of chlorophyll concentration in the lagoon and open ocean waters of New Caledonia. Mar. Pollut. Bull. 2010, 61, 503-518. [CrossRef] [PubMed]

42. Dupouy, C.; Frouin, R.; Röttgers, R.; Neveux, J.; Gallois, F.; Panché, J.Y.; Gerard, P.; Fontana, C.; Pinazo, C.; Ouillon, S.; et al. Ocean Color Response to an Episode of Heavy Rainfall in the Lagoon of New Caledonia. In Proceedings of the SPIE Conference Ocean Remote Sensing: Methods and Applications, San Diego, CA, USA, 19 August 2009; Volume 7459. [CrossRef]

43. Neveux, J.; Tenório, M.B.; Jacquet, S.; Torréton, J.P.; Douillet, P.; Ouillon, S.; Dupouy, C. Chlorophylls and phycoerythrins as markers of environmental forcings including cyclone Erica effect (March 2003) on phytoplankton in the southwest lagoon of New Caledonia and oceanic adjacent area. Int. J. Oceanogr. 2009, 2009, 19. [CrossRef]

44. Neveux, J.; Lefebvre, J.P.; Le Gendre, R.; Dupouy, C.; Gallois, F.; Courties, C.; Gérard, P.; Fernandez, J.M.; Ouillon, S. Phytoplankton dynamics in New Caledonian lagoon during a southeast trade winds event. J. Mar. Syst. 2010, 82, 230-244. [CrossRef]

45. Röttgers, R.; Dupouy, C.; Taylor, B.; Bracher, A.; Wozniak, S. Mass-specific light absorption coefficients of natural aquatic particles in the near-infrared spectral region. Limnol. Oceanogr. 2014, 59, 1449-1460. [CrossRef]

46. Wattelez, G.; Dupouy, C.; Mangeas, M.; Lefèvre, J.; Touraivane; Frouin, J.R. A Statistical Algorithm for Estimating Chlorophyll Concentration in the New Caledonian Lagoon. Remote Sens. 2016, 8, 45. [CrossRef]

47. Fuchs, R.; Pinazo, C.; Douillet, P.; Fraysse, M.; Grenz, C.; Mangin, A.; Dupouy, C. Modelling the ocean-lagoon interaction via upwelling processes on the South West of New Caledonia. Estuar. Coast. Shelf Sci. 2013, 135, 5-17. [CrossRef]

48. Minghelli-Roman, A.; Dupouy, C. Influence of water column chlorophyll concentration on bathymetric estimations in the lagoon of New Caledonia using several MERIS images. IEEE J. Sel. Top. Appl. Earth Obs. Remote Sens. 2013, 77, 1-7. [CrossRef]

49. Minghelli-Roman, A.; Dupouy, C. Seabed mapping in the lagoon of New Caledonia with MeRIS images. IEEE J. Sel. Top. Appl. Earth Obs. Remote Sens. 2014, 7, 2619-2629. [CrossRef]

50. Cravatte, S.; Kestenare, E.; Eldin, G.; Ganachaud, A.; Lefèvre, J.; Marin, F.; Menkes, C.; Aucan, J. Regional circulation around New Caledonia from two decades of observations. J. Mar. Syst. 2015, 148, $249-271$. [CrossRef]

51. Dublet, G.; Juillot, F.; Morin, G.; Fritsch, E.; Fandeur, D.; Brown, G.E., Jr. Goethite aging explains Ni depletion in upper units of ultramafic lateritic ores from New Caledonia. Geochim. Cosmochim. Acta 2015, 160, 1-15. [CrossRef]

52. Alory, G.; Vega, A.; Ganachaud, A.; Despinoy, M. Influence of upwelling, subsurface stratification, and heat fluxes on coastal sea surface temperature off southwestern New Caledonia. J. Geophys. Res. 2006, 111, C07023. [CrossRef]

53. Vega, A.; Ganachaud, A.; Bosson, J. Atlas Climatologique Satellite des Courants, vent, Elevation et Temperature en Surfasse dans Zone Economique Exclusive de Nouvelle-Caledonie; Elaboré par le Laboratoire d'Etudes Géophysiques et d'Océanographie Spatiale de L'Institut de Recherche pour le Développement (IRD): Nouméa, New Caledonia, 2005; pp. 1-27.

54. Maffione, R.A.; Dana, D.R. Instruments and methods for measuring the backward-scattering coefficient of ocean waters. Appl. Opt. 1997, 36, 6057-6067. [CrossRef] [PubMed]

55. Van Heukelem, L.; Thomas, C.S. Computer-assisted high-performance liquid chromatography method development with applications to the isolation and analysis of phytoplankton pigments. J. Chromatogr. 2001, 910, 31-49. [CrossRef] 
56. Röttgers, R.; Doerffer, R. Measurements of optical absorption by chromophoric dissolved organic matter using a point-source integrating-cavity absorption meter. Limnol. Oceanogr. Methods 2007, 5, 126-135. [CrossRef]

57. Mitchell, B. Algorithms for determining the absorption coefficient for aquatic particulates using quantitative filter technique. In SPIE, Ocean Optics X; SPIE: Orlando, FL, USA, 1990; Volume 1302, p. 12. [CrossRef]

58. Tassan, S.; Ferrari, G.M. An alternative approach to absorption measurements of aquatic particles retained on filters. Limnol. Oceanogr. 1995, 40, 1358-1368. [CrossRef]

59. Röttgers, R.; Häse, C.; Doerffer, R. Determination of the particulate absorption of microalgae using a point-source integrating-cavity absorption meter: Verification with a photometric technique, improvements for pigment bleaching and correction for chlorophyll fluorescence. Limnol. Oceanogr. Methods 2007, 5, 1-12. [CrossRef]

60. Pope, R.; Fry, E. Absorption spectrum (380-700 nm) of pure water. II. Integrating cavity measurements. Appl. Opt. 1997, 36, 8710-8723. [CrossRef] [PubMed]

61. Mueller, J.L. Overview of radiometric measurement and data analysis methods. In Ocean Optics Protocols for Satellite Ocean Color Sensor Validation; Mueller, J.L., Fargion, G.S., McClain, C.R., Eds.; NASA: Greenbelt, MD, USA, 2003; pp. 7-20.

62. Gordon, H.R.; Mccluney, W.R. Estimation of the Depth of Sunlight Penetration in the Sea for Remote Sensing. Appl. Opt. 1975, 14, 413-416. [CrossRef] [PubMed]

63. Rudorff, N.M.; Frouin, R.; Kampel, M.; Goyens, C.; Meriaux, X.; Schieber, B.; Mitchell, B.G. Ocean-color radiometry across the Southern Atlantic and Southeastern Pacific: Accuracy and remote sensing implications. Remote Sens. Environ. 2014, 149, 13-32. [CrossRef]

64. Froidefond, J.M.; Ouillon, S. Introducing a mini-catamaran to perform reflectance measurements above and below the water surface. Opt. Express 2005, 13, 926-936. [CrossRef] [PubMed]

65. Morel, A.; Antoine, D.; Gentili, B. Bidirectional reflectance of oceanic waters: Accounting for Raman emission and varying particle scattering phase function. Appl. Opt. 2002, 41, 6289-6306. [CrossRef] [PubMed]

66. Park, Y.J.; Ruddick, K. Model of remote-sensing reflectance including bidirectional effects for case 1 and case 2 waters. Appl. Opt. 2005, 44, 1236-1249. [CrossRef] [PubMed]

67. Hénin, C.; Cresswell, G.R. Upwelling along the western barrier reef of New Caledonia. Mar. Freshw. Res. 2005, 56, 1005-1010. [CrossRef]

68. Uitz, J.; Claustre, H.; Morel, A.; Hooker, S.B. Vertical distribution of phytoplankton communities in open ocean: An assessment based on surface chlorophyll. J. Geophys. Res. 2006, 111, C08005. [CrossRef]

69. Hirata, T.; Hardman-Mountford, N.J.; Brewin, R.J.W.; Aiken, J.; Barlow, R.; Suzuki, K.; Isada, T.; Howell, E.; Hashioka, T.; Noguchi-Aita, M.; et al. Synoptic relationships between surface Chlorophyll-a and diagnostic pigments specific to phytoplankton functional types. Biogeosciences 2011, 8, 311-327. [CrossRef]

70. Bricaud, A.; Claustre, H.; Ras, J.; Oubelkheir, K. Natural variability of phytoplanktonic absorption in oceanic waters: Influence of the size structure of algal populations. J. Geophys. Res. 2004, 109, C11010. [CrossRef]

71. Stramski, D.; Reynolds, R.A.; Kaczmarek, S.; Uitz, J.; Zheng, G. Correction of pathlength amplification in the filter-pad technique for measurements of particulate absorption coefficient in the visible spectral region. Appl. Opt. 2015, 54, 6763-6782. [CrossRef] [PubMed]

72. Maritorena, S.; Guillocheau, N. Optical properties of the water and spectral light absorption by living and non-living particles and by yellow substances in coral reef waters of French Polynesia. Mar. Ecol. Prog. Ser. 1996, 131, 245-255. [CrossRef]

73. Bricaud, A.; Babin, M.; Claustre, H.; Ras, J.; Tièche, F. Light absorption properties and absorption budget of Southeast Pacific waters. J. Geophys. Res. 2010, 115, C08009. [CrossRef]

74. Babin, M.D.; Stramski, G.M.; Ferrari, H.; Claustre, A.; Bricaud, G.; Obolensky, N. Hoepffner Variations in the light absorption coefficients of phytoplankton, nonalgal particles, and dissolved organic matter in coastal waters around Europe. J. Geophys. Res. 2003, 108, 3211. [CrossRef]

75. Weishaar, J.L.; Aiken, G.R.; Bergamaschi, B.A.; Fram, M.S.; Fujii, R.; Mopper, K. Evaluation of specific ultraviolet absorbance as an indicator of the chemical composition and reactivity of dissolved organic carbon. Environ. Sci. Technol. 2003, 37, 4702-4708. [CrossRef] [PubMed]

76. Gordon, H.R.; Ding, K. Self-shading of in-water optical instruments. Limnol. Oceanogr. 1992, 37, 491-500. [CrossRef] 
77. Stramski, D.; Tegowski, J. Effects of intermittent entrainment of air bubbles by breaking wind waves on ocean reflectance and underwater light field. J. Geophys. Res. 2001, 106, 345-360. [CrossRef]

78. Zibordi, G.; Berthon, J.; D'Alimonte, D. An Evaluation of Radiometric. Products from Fixed-Depth and Continuous In-Water Profile Data from Moderately Complex Waters. J. Atmos. Ocean. Technol. 2009, 26, 91-106. [CrossRef]

79. Stramska, M.; Dickey, T. Short-term variability of the underwater light field in the oligotrophic ocean in response to surface waves and clouds. Deep-Sea Res. Part I Oceanogr. Res. Pap. 1998, 45, 1393-1410. [CrossRef]

80. Green, R.E.; Sosik, H.M. Analysis of apparent optical properties and ocean color algorithms using measurements of seawater constituents in New England continental shelf surface waters. J. Geophys. Res. 2004, 109, C03026. [CrossRef]

81. Tzortziou, M.; Herman, J.R.; Gallegos, C.L.; Neale, P.J.; SubRamaniam, A.; Harding, L.W., Jr. Bio-optics of the Chesapeake Bay from measurements and radiative transfer closure. Estuar. Coast. Shelf Sci. 2006, 68, 348-362. [CrossRef]

82. Lee, Z.P.; Du, K.; Voss, K.J.; Zibordi, G.; Lubac, B.; Arnone, R.; Weidemann, A. An inherent-optical-property-centered approach to correct the angular effects in water-leaving radiance. Appl. Opt. 2011, 50, 3155-3167. [CrossRef] [PubMed]

83. Westberry, T.K.; Boss, E.; Lee, Z. Influence of Raman Scattering in ocean color inversion models. Appl. Opt. 2013, 52, 5552-5561. [CrossRef] [PubMed]

84. Loisel, H.; Lubac, B.; Dessailly, D. Effect of inherent optical properties variability on the chlorophyll retrieval from ocean color remote sensing: An in situ approach. Opt. Express 2010, 18, 20949-20959. [CrossRef] [PubMed]

85. Szeto, M.; Werdell, P.J.; Moore, T.S.; Campbell, J.W. Are the world's oceans optically different? J. Geophys. Res. 2011, 116, C00H04. [CrossRef]

86. Mobley, C.D. Estimation of the remote-sensing reflectance from above-surface measurements. Appl. Opt. 1999, 38, 7442-7455. [CrossRef] [PubMed]

87. Ruddick, K.G.; De Cauwer, V.; Park, Y.; Moore, G. Seaborne measurements of near infrared water-leaving reflectance: The similarity spectrum for turbid waters. Limnol. Oceanogr. 2006, 51, 1167-1179. [CrossRef]

88. Neukermans, G. Optical In Situ and Geostationary Satellite-Borne Observations of Suspended Particles in Coastal Waters. Ph.D. Thesis, Université du Littoral-Côte d'Opale, Wimereux, France, 2012. 